\title{
La potestad sancionadora de la Administración en el ámbito laboral
}

\author{
Susana Rodríguez Escanciano ${ }^{1}$
}

Sumario: I. APROXIMACIÓN AL RÉGIMEN JURÍDICO APLICABLE. II. LOS PRINCIPIOS BÁSICOS DEL PROCEDIMIENTO ADMINISTRATIVO SANCIONADOR Y SU PROYECCIÓN EN EL ORDEN SOCIAL. 1. Principio de legalidad. 2. Principio de tipicidad. 3. Principio non bis in idem. 4. Principio de culpabilidad. 5. Principio de proporcionalidad. III. SUJETOS RESPONSABLES. IV. INFRACCIONES. 1. Graduación. 2. Prescripción. V. SANCIONES. 1. Clases. 2. Atenuantes y agravantes. VI. PROCEDIMIENTO SANCIONADOR. 1. Comprobación del cumplimiento de las normas sociales. 2. Las actas de infracción. 3. Alegaciones. 4. Resolución. VII. CONCLUSIÓN.

\section{APROXIMACIÓN AL RÉGIMEN JURÍDICO APLICABLE}

En buen número de ocasiones, los sujetos obligados a cumplir las previsiones del ordenamiento laboral lo hacen de forma pacífica, sin intervención de mecanismo externo alguno. Pero la realidad demuestra que con frecuencia se producen vulneraciones de lo que la norma ordena, lo cual hace necesario la introducción de un sistema de garantía, que conlleva el establecimiento de un elemento coactivo confiado, por un lado, a la jurisdicción y, por otro, a la Administración.

En el ejercicio de la potestad que el art. 25.1 CE atribuye a la segunda, ésta tiene el poder de imponer "un mal" a un administrado "como consecuencia de una conducta ilegal" realizada, en lo que aquí interesa, sobre el llamado "orden social”2. Obviamente, si hablamos de aparato administrativo sancionador en el terreno de lo laboral debemos trasladar el centro de atención a la Ley de Infracciones y Sanciones del Orden Social, cuya versión vigente se contiene en el Texto Refundido, aprobado por Real Decreto Legislativo 5/2000, de 4 de agosto (LISOS).

1 Profesora Titular de Derecho del Trabajo y de la Seguridad Social. Universidad de León. Acreditada para el acceso al Cuerpo de Catedráticos.

2 Cámara Botía, A.: “La potestad sancionadora de la Administración en el orden social: cuestiones generales”, en AA.VV (Cavas Martínez, F. y Luján Alcaraz, J., Dirs.): Infracciones y sanciones en el orden social. Régimen jurídico, Murcia (Laborum), 2009, p. 21. 
Superando determinadas fuerzas centrífugas del pasado, y como quiere dar a entender su ambiciosa denominación, la LISOS ha tratado de codificar y reunir en su seno todas las infracciones de carácter administrativo en la materia. Puede decirse, así, que esta Ley presenta en la actualidad la fisonomía de un verdadero código de las infracciones y sanciones en el orden social, con afán completo y sistemático y, va de suyo, con una declarada sujeción a los principios generales de legalidad y tipicidad³. Como señala su brevísima exposición de motivos, en ella se integran, "debidamente regularizadas, aclaradas y sistematizadas", el conjunto de disposiciones legales en su día señaladas por la norma de delegación, la Ley 55/1999, de 29 de diciembre, de Medidas Fiscales, Administrativas y del Orden Social, incluida, lógicamente, la Ley 8/1988, de 8 de abril, precedente inmediato de la actual ${ }^{4}$.

Tal pretensión de sistematización y codificación del conjunto de infracciones del orden social conlleva una cuádruple consecuencia5:

1. Dentro de la LISOS se han ubicado todas aquellas previsiones legales sobre infracciones y sanciones administrativas que en otros momentos pudieron figurar en las correspondientes disposiciones sustantivas (tal y como sucedió -en paradigmático ejemplo- con la Ley 31/1995, de 8 de noviembre, de Prevención de Riesgos Laborales -LPRL-).

2. A ella se deben ir incorporando, como de hecho se viene haciendo en los últimos años, todas aquellas reformas legales en las que la regla sustantiva de referencia aparece acompañada de la oportuna previsión sancionadora (Ley 10/1997, de 24 de abril, sobre derechos de información y consulta de los trabajadores en las empresas y grupos de empresas de dimensión comunitaria; Ley 45/1999, de 29 de noviembre, sobre desplazamiento de trabajadores en el marco de una prestación de servicios transnacional; Ley 31/2006, de 18 de octubre, sobre implicación de los trabajadores en las sociedades anónimas y cooperativas europeas; Ley 32/2006, de 18 de octubre, de subcontratación en el sector de la construcción; Ley 43/2006, de 29 de diciembre, de medidas fiscales, administrativas y del orden social; Ley Orgánica 3/2007, de 22 de marzo,

3 Fernández Márquez, O. y García Murcia, J.: “Infracciones extrasistemáticas del empresario en materia social”, Revista del Ministerio de Trabajo y Asuntos Sociales, núm. 78, 2008, p. 71.

4 Cavas Martínez, F. y Luján Alcaraz, J.: “Presentación”, en AA.VV (Cavas Martínez, F. y Luján Alcaraz, J., Dirs.): Infracciones y sanciones en el orden social. Régimen jurídico, Murcia (Laborum), 2009, p. 16. Sobre la Ley 8/1998, entre otros, Montalvo Correa, J.: "La Ley 8/1988, de 7 de abril, sobre infracciones y sanciones en el orden social”, Documentación Laboral, núm. 25, 1988, pp. 263 y ss.; Pradas Montilla, R. y Martín Serrano, A.L.: "Algunas reflexiones sobre la Ley de Infracciones y Sanciones en el orden social y su desarrollo", Documentación Laboral, núm. 26, 1988, pp. 41 y ss.; Páramo Montero, P.: “Comentario a la Ley 8/1988, de 7 de abril, sobre Infracciones y Sanciones en el orden social: infracción y responsabilidad”, Revista Española de Derecho del Trabajo, núm. 54, 1992, pp. 505 y ss.; De Alcántara y Colón, J.M.: “La Ley 8/1988, de 7 de abril, sobre Infracciones y sanciones en el orden social”, La Ley, núm. 3, 1994, pp. 949 y ss. ó Vázquez Mateo, F.: “La nueva reforma de la Ley 8/1988, de 7 de abril, sobre Infracciones y Sanciones en el orden social”, Actualidad Laboral, núm. 1, 1994, pp. 229 y ss.

5 Fernández Márquez, O. y García Murcia, J.: “Infracciones extrasistemáticas del empresario en materia social", cit., p. 72. 
para la Igualdad Efectiva de Mujeres y Hombres; Ley 44/2007, de 13 de diciembre, para la regulación del régimen de empresas de inserción; Ley 2/2008, de 23 de diciembre, de presupuestos generales del Estado para 2009 o, entre otras, Real Decreto Ley 10/2010, de 16 de junio, de medidas urgentes para la reforma del mercado de trabajo).

3. Funciona como una especie de plataforma sancionadora para los casos de incumplimiento de las reglas de contenido social procedentes de leyes especiales que han carecido desde el principio de aparato sancionador administrativo propio (como ha sucedido con la Ley Orgánica 11/1985, de 2 de agosto, de Libertad Sindical, o con el Real Decreto-Ley 17/1977, de 4 de marzo, de Relaciones de Trabajo) ${ }^{6}$.

4. Actúa como norma de referencia o de remisión en aquellos supuestos en los que la regulación sustantiva se sitúa en la frontera -o justo en el borde- de lo social, rozándole pero sin causarle afectación en sentido propio (como sucede con la Ley 49/2007, de 26 de diciembre, sobre régimen sancionador en materia de igualdad de oportunidades, no discriminación y accesibilidad universal de las personas con discapacidad, que reconduce a la LISOS aquellos comportamientos acontecidos en el terreno perteneciente al orden aquí analizado).

Ahora bien, pese al enorme avance que ha supuesto la promulgación de la LISOS, en cuanto pretende integrar en una sola norma la práctica totalidad de infracciones y sanciones que confluyen en un mismo ámbito jurídico (el de las relaciones de trabajo en sentido amplio), no queda más remedio que denunciar la insuficiencia parcial de su ámbito material, toda vez que algunas disposiciones sancionadoras de rango legal permanecen todavía fuera de la misma. Pese a la amplitud del mandato refundidor y a su técnica mixta (lista de normas más cláusula abierta), el propio legislador delegado acepta que no va a llevar hasta sus últimas consecuencias el encargo que se le hizo; no de otro modo ha de interpretarse el propio art. 1.1 LISOS cuando define las infracciones administrativas en el orden social como las acciones $u$ omisiones de los distintos sujetos responsables que estén "tipificadas y sancionadas en la presente Ley y en las leyes del orden social". Existen, por tanto, leyes y normas de contenido sancionador laboral cuyo régimen jurídico no forma parte de la LISOS.

Buena prueba de lo afirmado puede encontrarse en los cinco supuestos siguientes?:

1. Lugar destacado y principal ocupan las dos circunstancias a continuación expuestas: de un lado, el régimen de infracciones y sanciones en el ámbito de la actividad transnacional de las empresas de trabajo temporal, el cual aparece recogido en los arts. 24, 25 y 27 de la Ley 14/1994, de 1 de junio; de otro, con la excepción de las contravenciones en materia de permisos de trabajo de los extranjeros del art. 37

6 Martínez Lucas, J.A.: “La nueva Ley sobre infracciones y sanciones en el orden social”, La Ley, núm. 6, 2000, pp. 2050 y ss.

7 Areta Martínez, M. y Sempere Navarro, A.V.: “La codificación de las infracciones y sanciones en el orden social”, Revista del Ministerio de Trabajo y Asuntos Sociales, núm. 78, 2008, p. 73. 
LISOS, las infracciones y sanciones existentes en materia de extranjería se contienen en los arts. 46 y ss. de la Ley Orgánica 4/2000, de 11 de enero, sobre Derechos y Libertades de los Extranjeros en España y su Integración Social ${ }^{8}$.

2. Con la constitución del Estado de las Autonomías hemos asistido a un complejo proceso de diversificación orgánica y funcional del ejercicio del poder sancionador, merced a la asunción creciente de potestades punitivas por parte de las Comunidades Autónomas. Aunque el Derecho Administrativo sancionador en materia laboral es competencia exclusiva del Estado, pues forma parte de la "legislación laboral" a que se refiere el art. 149.1.7. ${ }^{a} \mathrm{CE}$, los Entes territoriales autonómicos, en virtud de lo previsto en sus respectivos Estatutos, y con fundamento en las reglas $7 .^{a}$ y $17 .{ }^{a}$ del propio art. 149.1 CE (que les permite asumir prerrogativas en orden a la "ejecución de la legislación laboral y de Seguridad Social”), pueden intervenir ejerciendo la potestad sancionadora respecto de aquellos incumplimientos que no se refieran a materias de la exclusiva atribución estatal ${ }^{9}$. Al margen de la LISOS quedan también aquellos aspectos relacionados con la asistencia social externa al sistema de Seguridad Social

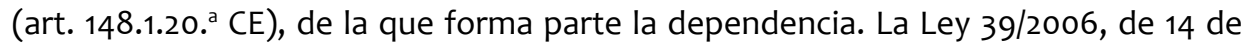
diciembre, de Promoción de la Autonomía Personal y Atención a las personas en situación de Dependencia, actúa, así, como pieza angular, desgranando, a lo largo de los seis artículos que integran su título III, la identificación de los sujetos responsables (art. 42), la tipificación de las infracciones (art. 43) y su clasificación (art. 44), el régimen de prescripción (art. 46) y la atribución de competencia sancionadora a los diversos órganos administrativos (art. 47) ${ }^{10}$.

3. No faltan, en nuestro ordenamiento jurídico, otras muchas normas que formalmente no están adscritas al segmento que conocemos como derecho social, pero que tipifican infracciones en las que pueden incurrir quienes emplean a trabajadores por cuenta ajena, y que, en consecuencia, pueden coadyuvar también a la finalidad de protección de los derechos o intereses laborales de los sujetos implicados. Los incumplimientos tipificados en todas estas leyes no laborales no pueden calificarse estrictamente, como es natural, como infracciones del orden social, pues se sitúan extramuros de la LISOS. Pero, desde una perspectiva material, no dejan de presentar una innegable e interesante dimensión social; a fin de cuentas, habrán de tenerse en cuenta, en cualquier caso, para el buen conocimiento y la adecuada aplicación de esta rama

8 Camas Roda, F.: “La dispersión de las infracciones laborales relativas al trabajo de extranjeros: análisis de la compatibilidad entre las sanciones derivadas de la comisión de infracciones previstas en la Ley de Infracciones y Sanciones del Orden Social y en la Ley de Extranjería", Revista Española de Derecho del Trabajo, núm. 116, 2003, pp. 191 y ss.

9 Cavas Martínez, F.: “La tutela sancionadora en materia laboral: de la Ley 8/1988, de 7 de abril, sobre Infracciones y Sanciones del Orden Social, al Real Decreto Legislativo 5/2000, de 4 de agosto, que aprueba el texto refundido de la Ley de Infracciones y Sanciones en el Orden Social (II)", Aranzadi Social, T. V, 2000, p. 254. Al respecto, también, STCo 195/1996, de 28 de noviembre, comentada por Martínez Gayoso, M.N.: “La potestad sancionadora autonómica en el orden social”, Revista Vasca de Administración Pública, núm. 50, 1998, pp. 329 y ss.

10 Sánchez Trigueros, C. y González Díaz, F.A. "Sobre las infracciones y sanciones (estatales y autonómicas) en materia de Dependencia”, Aranzadi Social, núm. 1, 2008 (BIB 2008, 499). 
del derecho. Cabe hacer referencia, así, a efectos meramente ilustrativos, a la Ley Orgánica 15/1999, de 13 de diciembre, de protección de datos de carácter personal, la Ley 23/1992, de 30 de julio, de seguridad privada, la Ley 16/1987, de 30 de julio, de ordenación del transporte terrestre, la Ley $28 / 2005$, de 26 de diciembre, de medidas sanitarias frente al tabaquismo, o la Ley $25 / 1964$, de 29 de abril, sobre energía nuclear ${ }^{11}$.

4. La detección de infracciones y la imputación efectiva de responsabilidad por su comisión requieren un aparato orgánico y un procedimiento capaces de permitir llevar a término tales operaciones. Deviene necesario, por tanto, hacer referencia, en primer lugar, a las normas reguladoras de la Inspección de Trabajo, por ser éstos los funcionarios destinados a cumplir la esencial función de detectar infracciones en el orden social y proponer sus correspondientes sanciones, con independencia de que sus cometidos no se agoten en estas funciones. Su organización y el desarrollo de su actividad se contemplan, en concreto, en la Ley 42/1997, de 14 de noviembre, de Ordenación de la Inspección de Trabajo y Seguridad Social (LIT), y en el Real Decreto 138/2000, de 4 de febrero, que aprueba su Reglamento de Organización y Funcionamiento ${ }^{12}$.

Procede aludir, en segundo término, a las disposiciones reguladoras de los procedimientos de imposición de sanciones administrativas por infracciones en el orden social, que no se refieren al común regulado en la Ley 30/1992, de 26 de noviembre, de Régimen Jurídico de las Administraciones Públicas y del Procedimiento Administrativo Común (LRJAP), desarrollado por el Real Decreto 1398/1993, de 4 de agosto, sin perjuicio de su aplicación supletoria (conforme a la disposición adicional 8. ${ }^{\text {a }}$ LRJAP, art. 1.3 RD 1398/1993 y art. 51.2 LISOS) ${ }^{13}$. Antes al contrario, el procedimiento para la imposición de sanciones por infracciones en el orden social queda configurado como un procedimiento especial, cuyo desarrollo ha tenido lugar a través de una norma también singular cual es el Real Decreto 928/1998, de 14 de mayo, disposición a la que se deben sumar las reglas de procedimiento incorporadas a la propia LISOS en su capítulo VII (arts. 48 a 54) o a la LIT (en paradigmático ejemplo, la disposición adicional $4 .^{\text {a }}$ ), sin olvidar la aplicación del Real Decreto 707/2002, de 19 de julio, cuando las infracciones consistan en incumplimientos de la Administración en materia de prevención de riesgos (de conformidad con lo previsto en el art. 51 LISOS y en la disposición adicional $4 \cdot^{\text {a }}$ de la ya citada LIT $)^{14}$.

5. En fin, conviene no olvidar cómo todavía, al día de hoy, la jurisdicción competente para conocer de la impugnación de las sanciones por infracciones de carác-

11 Fernández Márquez, O. y García Murcia, J.: “Infracciones extrasistemáticas del empresario en materia social", cit., p. 63.

12 Minondo Sanz, J.: Fundamentos de la Inspección de Trabajo y Seguridad Social, Madrid (MTAS), 2000, pp. 115 y ss.

13 Garberí Llobregat, J.: El procedimiento administrativo sancionador (Comentarios al título IX de la Ley 30/1992 y al Reglamento del Procedimiento para el ejercicio de la potestad sancionadora de la Administración), Valencia (Tirant Lo Blanch), 1996, pp. 57 y ss.

14 Fernández Márquez, O. y García Murcia, J.: “Infracciones extrasistemáticas del empresario en materia social", cit., p. 63. 
ter social es la contencioso administrativa, regulada en la Ley 29/1998, de 13 de diciembre (LJCA); y es que aun cuando tanto la disposición adicional $5 .^{\text {a }}$ de esta disposición legal como la Ley 50/1998, de 30 de diciembre, de Medidas Fiscales, Administrativas y del Orden Social, ordenaron la reforma del art. 3 del Real Decreto Legislativo 2/1995, de 7 de abril, por el que se aprueba el texto refundido de la Ley de Procedimiento Laboral ( $L P L)$, a fin de que los órganos jurisdiccionales del orden social conocieran de las pretensiones sobre "las resoluciones administrativas relativas a la imposición de cualesquiera sanciones por todo tipo de infracciones de orden social, con las excepciones previstas en la letra b) del apartado 1 de este artículo", lo cierto es que el Gobierno ha incumplido la obligación de remitir a las Cortes un Proyecto de Ley para incorporar a la LPL las modalidades y especialidades procesales correspondientes y determinar al mismo tiempo la fecha de entrada en vigor de la atribución a la jurisdicción social de las materias referidas ${ }^{15}$.

\section{LOS PRINCIPIOS BÁSICOS DEL PROCEDIMIENTO ADMINISTRATIVO SANCIONADOR Y SU PROYECCIÓN EN EL ORDEN SOCIAL}

Bajo la premisa de que los parámetros inspiradores del orden penal son de aplicación, con ciertos matices, al Derecho Administrativo Sancionador ${ }^{16}$, el legislador, aprovechando el marco de la adaptación normativa del régimen jurídico de las Administraciones Públicas a los principios constitucionales operada a través de la LRJAP, introdujo en la misma un título, el IX, dedicado a la potestad sancionadora, cuyo objeto era regular los postulados básicos a que debe someterse el ejercicio de la potestad sancionadora de la Administración y los correspondientes derechos que de los mismos se derivan para los ciudadanos, extraídos del texto constitucional y de la consolidada jurisprudencia interpretativa de la norma fundamental ${ }^{17}$.

De este modo, el primer capítulo del título IX LRJAP, rubricado principios de la potestad sancionadora, recoge expresamente los de legalidad y tipicidad, así como una consecuencia de los mismos cual es la irretroactividad en su doble vertiente: por un lado, la interdicción de aplicación retroactiva de disposiciones sancionadoras y, paralelamente, por otro, el reconocimiento de que las disposiciones sancionadoras producirán efecto retroactivo en cuanto favorezcan al presunto infractor ${ }^{18}$. Igualmente se recogen los principios de culpabilidad, proporcionalidad y non bis in idem,

15 Desdentado Bonete, A.: "La nueva jurisdicción contencioso-administrativa y el orden social ¿una reforma frustrada?”, Revista de Derecho Social, núm. 7, 1999, pp. 25-26 ó Soro Mateo, B.: “La competencia para la revisión judicial de las resoluciones sancionadoras de infracciones de orden social: trasvase competencial operado en virtud de la Ley 29/1998, de 13 de julio", Aranzadi Social, T. V, 1999, pp. 729 y ss.

16 Por todas, STCo 18/1981, de 8 de junio.

17 Blasco Pellicer, A.: Sanciones administrativas en el orden social, Valencia (Tirant Lo Blanch), 1998, p. 54 .

18 Chinchilla Marín, C.: “Potestad sancionadora de las Administraciones Públicas”, en AA.VV (Pendás García, B., Dir.): Administraciones Públicas y ciudadanos (Estudio sistemático de la Ley 30/1992, de 26 de $204 \begin{aligned} & \text { noviembre, de Régimen Jurídico de las Administraciones Públicas y del Procedimiento Administrativo Común), } \\ & \text { Barcelona (Praxis), 1993, pp. } 754 \text { y ss. }\end{aligned}$ 
regulándose por último la prescripción de las infracciones y faltas desde la perspectiva de que tal regulación forma parte de la conformación del tipo y, consecuentemente, queda sujeta al principio de reserva de ley ${ }^{19}$.

Por su parte, en el segundo capítulo, los arts. 134 a 138 desarrollan los principios del procedimiento sancionador, partiendo de dos ideas clave: de un lado, el ejercicio de la potestad punitiva requerirá el procedimiento legal o reglamentariamente establecido y, de otro, la imposibilidad de imponer sanción sin haber seguido el oportuno iter procedimental. Se regulan, además, los derechos del presunto responsable, con especial detenimiento en el de presunción de inocencia, y las prerrogativas y facultades de la Administración en dicha tramitación ${ }^{20}$.

Como no podía ser de otra manera, los límites de un trabajo de estas características obligan a realizar un importante esfuerzo de síntesis a la hora de analizar la extrapolación de tales principios y garantías al ámbito del Derecho sancionador administrativo en el orden social, incidiendo exclusivamente en aquellos aspectos dotados de mayor singularidad:

\section{Principio de legalidad}

Formulado en el art. 25.1 CE y reiterado por el art. 127.1 LRJAP, supone que "nadie puede ser condenado o sancionado por acciones $u$ omisiones que en el momento de producirse no constituyan delito, falta o infracción administrativa, según la legislación vigente en aquel momento" ${ }^{21}$, lo cual significa, de acuerdo con la jurisprudencia constitucional $^{22}$, la necesaria cobertura de la potestad sancionadora administrativa por una norma de rango legal ${ }^{23}$, que no excluye remisiones por parte de la ley a normas reglamentarias, siempre que ello se haga de forma subordinada a la primera ${ }^{24}$. Esta reserva legal impuesta por la Carta Magna no significa tampoco que queden invalidadas las normas sancionadoras con carácter reglamentario anteriores a la propia Norma Fundamental, dictadas de acuerdo con el sistema a la sazón vigente y, por ende, válidas, en tanto en cuanto ello supone la inexistencia de efecto retroactivo de la exigencia de una norma de cobertura de rango legal 25 .

19 Nieto García, A.: Derecho Administrativo Sancionador, Madrid (Tecnos), 1994, p. 137.

20 Garrido Falla, F. y Fernández Pastrana, J.M.: Régimen Jurídico y Procedimiento de las Administraciones Públicas (Un estudio de las Leyes 30/1992 y 4/1999), Madrid (Civitas), 2000, pp. 351 y ss.

21 En general sobre la potestad sancionadora de los poderes públicos, Garrido Falla, F.: “Los medios de la policía y la teoría de las sanciones administrativas", Revista de Administración Pública, núm. 28, 1959, pp. 11 y ss., o Nieto García, A.: “Problemas capitales del Derecho disciplinario”, Revista de Administración Pública, núm. 63, 1970, pp. 39 y ss.

22 STCo 77/1983, de 3 de octubre.

23 Del Rey Guanter, S.: "Los principios de legalidad y tipicidad en las infracciones del orden social”, Relaciones Laborales, T. II, 1991, pp. 495 y ss.

24 STCO 42/1987, de 7 de abril.

25 STS, Cont-Admtivo, 15 marzo 1990 (RJ 2021). 
A pesar de tales previsiones, la LISOS parece haber optado por no hacer un uso excesivo de la colaboración de la regulación reglamentaria en el establecimiento de las conductas sancionables, como se comprueba en la existencia de dos únicas remisiones expresas a este tipo de norma infralegal (disposición adicional 1. a , en relación a la actualización de las cuantías de las sanciones, y disposición adicional 2.a , que establece el mandato al Gobierno para que dicte un Reglamento sobre el procedimiento para la imposición de sanciones). Seguramente, fueron los antecedentes de anulación judicial de normas sancionadoras irrespetuosas con el principio de legalidad ${ }^{26}$ los que determinaron una opción de política legislativa caracterizada por escasas -aunque no inexistentes-remisiones al desarrollo reglamentario, lo que ha significado un robustecimiento del principio de reserva de ley formal en la materia; y también la opción por un minucioso casuismo y por el criterio del numerus clausus en la tipificación de las infracciones (con la enumeración de supuestos concretos o el establecimiento de pautas de cierta generalidad que permiten identificar los comportamientos sancionables) ${ }^{27}$.

La consecuencia de este impulso del principio de reserva de ley formal ha sido -siguiendo a la doctrina más autorizada- la "petrificación” de las conductas sancionables y la "esclerotización” de los tipos, impidiendo que por vía reglamentaria pudiera operarse la necesaria adaptación a las modificaciones de una materia tan dinámica y compleja como lo es la legislación social ${ }^{28}$. Buena prueba de ello han sido las sucesivas reformas, referidas supra, de las que ha sido objeto la LISOS desde su versión originaria, muchas de las cuales han procedido a una reformulación de los tipos infractores con la finalidad de abarcar conductas no previstas en el momento de la formulación primigenia.

Cuestión más delicada es la posibilidad de aplicar sanciones derivadas del incumplimiento de convenios colectivos, admitida por el art. 5.1 LISOS con las siguientes matizaciones: a) No son controlables administrativamente las transgresiones de puras cláusulas contractuales, no en vano los denominados convenios colectivos extraestatutarios tienen eficacia contractual y no normativa ${ }^{29}$. b) Sólo serán fiscalizables los incumplimientos del contenido normativo (relativo fundamentalmente a las condiciones de trabajo), no del contenido obligacional, referido a las relaciones de los sujetos negociadores ${ }^{30}$. c) No todo incumplimiento del contenido normativo de los

26 Sobre la base de la vulneración de este principio, se declaró en su día la nulidad de pleno derecho del Real Decreto 2347/1985, de 4 de diciembre, que había aprobado un catálogo de infracciones laborales en desarrollo del art. 57 ET, en su redacción original de 1980. STS, Cont-Admtivo, 10 noviembre 1986 (RJ 6647).

27 Monereo Pérez, J.L. y Fernández Avilés, J.A.: “El Derecho Administrativo sancionador del trabajo: principios y rasgos constitutivos”, en AA.VV (García Blasco, J. y Monereo Pérez, J.L., Dir.): Comentario sistemático al texto refundido de la Ley de Infracciones y Sanciones en el orden social y normas concordantes, Granada (Comares), 2006, p. 17.

28 García Blasco, J.: "Potestad sancionadora de la Administración en materia laboral y principio de legalidad”, Revista Española de Derecho del Trabajo, núm. 26, 1986, pp. 209 y ss.

29 Sala Franco, T.: “La negociación colectiva en España”, en AA.VV.: Guía de la negociación colecti va, Madrid (MTAS), 2006, p. 40.

30 SSTS, Social, 21 diciembre 1994 (RJ 10346) ó 29 abril 2003 (RJ 4073). 
convenios colectivos será infracción social, pues únicamente cuando se definen las infracciones laborales (capítulo II LISOS) se incluye la referencia a las normas paccionadas; todo lo contrario sucede cuando se describen las contravenciones en materia de Seguridad Social donde no se incluye referencia alguna a los pactos colectivos (art. 20 LISOS) ${ }^{31}$. d) En fin, sólo en los casos de remisión de la ley o del reglamento a la norma convencional, o cuando el propio convenio precise y detalle un incumplimiento ya tipificado en la Ley, cabe la imposición de sanciones administrativas ${ }^{32}$.

\section{Principio de tipicidad}

Formulado por el art. 129 LRJAP, exige que las acciones u omisiones consideradas como infracciones se delimiten de forma precisa, lo que no hay que entender de manera rígida y absoluta en el sentido de una determinación siempre minuciosa y exhaustiva, puesto que se admite la utilización de cierto margen de apreciación ${ }^{33}$, circunstancia de especial aplicación en el ámbito laboral constituido por prolijas normas definidoras de derechos y obligaciones de los sujetos incluidos en su ámbito de aplicación ${ }^{34}$.

No es necesario, por tanto, que el precepto legal realice una definición absoluta cuando la conducta ilícita que se pretende perseguir se resista, por su extensión, complejidad e imprevisibilidad, a ser regulada con exhaustividad, bastando cuando ello ocurra con el uso de otras técnicas de regulación, como pudieran ser los conceptos jurídicos indeterminados o el reenvío a otros grupos normativos ${ }^{35}$. No es posible, sin embargo, extender por vía analógica el ámbito de la infracción aplicando el tipo establecido para una determinada conducta a otra distinta ${ }^{36}$.

Así, aun cuando la LISOS se caracteriza por hacer una configuración precisa de la mayoría de las conductas sancionables, no faltan ejemplos de tipos infractores abiertos o -en muchas menos ocasiones- que remiten a la norma reglamentaria y a la convencional para su completa comprensión. Cabe aludir así, en primer término, a lo previsto en el art. 6.4, que califica como infracción leve, con expresa remisión al reglamento, "no informar por escrito al trabajador sobre los elementos esenciales del contrato y las principales condiciones de ejecución de la prestación laboral, en los términos o plazos establecidos reglamentariamente"; o el art. 10.4, que define como

31 Cámara Botía, A.: “La potestad sancionadora de la Administración en el orden social: cuestiones generales", cit., pp. 53-54.

32 Gutiérrez-Solar Calvo, B.: “¿Deberes públicos de origen convencional?”, Revista Española de Derecho del Trabajo, núm. 97, 1999, p. 119.

33 STCo 62/1982, de 15 de octubre.

34 Del Rey Guanter, S.: "Los principios de legalidad y tipicidad en las infracciones del orden social", cit., pp. 501 y ss.

35 Mateos Beato, A. y González de Lena, F.: “El texto refundido de la LISOS. Orígenes, orientaciones y contenido", Relaciones Laborales, núm. 6, 2001, p. 40.

36 STS, Cont-Admtiva, 12 diciembre 1997 (RJ 8869). 
infracción administrativa "no garantizar a los trabajadores desplazados a España las condiciones de trabajo previstas por la ley, en las disposiciones reglamentarias o en los convenios colectivos aplicables".

En segundo lugar, la LISOS utiliza también conceptos jurídicos indeterminados para clasificar, de forma general, las infracciones en leves, graves y muy graves. En tal sentido, se consideran "leves" aquéllas que carezcan de "trascendencia grave" para la integridad de los trabajadores, "graves" aquéllas que supongan "un riesgo grave para la actividad física o la salud de los trabajadores afectados", y finalmente "muy graves" aquellas conductas empresariales que supongan un riesgo "grave e inminente" para la seguridad y salud de los trabajadores ${ }^{37}$.

\section{Principio non bis in idem}

Expresado por el art. 133 LRJAP, implica que unos mismos hechos no pueden ser objeto de una duplicidad de sanciones, penal y administrativa, "inadmisible reiteración del ejercicio de la facultad sancionadora del Estado" 38. La aplicación de este principio supone que la actuación sancionadora de la Administración debe ceder ante la intervención de los Tribunales: si éstos estiman que ha habido delito o falta, queda cerrada la actuación sancionadora administrativa, pudiendo actuar la Administración en caso contrario, pero basándose en los hechos comprobados por los Tribunales en el correspondiente proceso penal ${ }^{39}$.

En desarrollo de las directrices expresadas por la doctrina constitucional, el art. 3 LISOS establece expresamente la imposibilidad de castigar los hechos que hayan sido sancionados penal o, incluso, administrativamente, en los casos en que se aprecie identidad de sujeto, de hecho y de fundamento ${ }^{40}$. En todo caso, la necesidad de que se produzca esta triple coincidencia explica la dificultad de aplicar el principio non bis in idem en el ámbito social ${ }^{41}$.

Aunque la regla atiende fundamentalmente a la relación entre sanción penal y administrativa (prohibiendo la imposición de una doble sanción penal y administrativa a un mismo sujeto en atención a un mismo incumplimiento de la legislación laboral), no cabe olvidar que el principio aquí analizado también tiene virtualidad entre

37 Camas Roda, F.: “Las infracciones y sanciones administrativas del empresario en el orden social”, Revista Trabajo y Seguridad Social (Centro de Estudios Financieros), núm. 254, 2004, p. 9.

38 SSTCo 77/1983, de 3 de octubre, y 159/1985, de 27 de noviembre.

39 STCo 2/1981, de 30 de enero. En el mismo sentido, STS, Cont-Admtivo, 16 julio 2008 (RJ 6802).

40 Arroyo Zapatero, L.A.: "El ne bis in idem en las infracciones al orden social, la prevención de riesgos laborales y los delitos contra los derechos de los trabajadores y la Seguridad Social”, en AA.VV (Picó Lorenzo, C., Dir.): Las fronteras del Código Penal y el Derecho Administrativo Sancionador, Madrid (CGPJ), 1997, pp. 287 y ss.

41 Del Rey Guanter, S.: Potestad sancionadora de la Administración y jurisdicción penal en el orden social, Madrid (MTSS), 1990, pp. 15 y ss. 
sanciones administrativas ${ }^{42}$. De esta forma, si se trata de Administraciones diferentes, podrían abrirse dos procedimientos paralelos al amparo de normas igualmente aplicables. Tratándose de órganos distintos de una misma Administración, el superior jerárquico común decidirá cuál de los dos debe continuar y cuál debe ser paralizado, o si deben proseguir los dos. En fin, cuando se trate de dos Administraciones distintas, cada una de ellas decidirá por separado si paraliza o continúa el expediente. En todo caso -como ya consta-, la viabilidad del principio queda sujeta a la necesaria identidad de fundamento jurídico, lo cual resulta difícil en el marco del orden social, de manera que, en la práctica, sería viable la imposición de doble sanción administrativa donde se encuentra en juego la tutela de diversos bienes jurídicos a proteger ${ }^{43}$.

Sea como fuere, el principio non bis in idem tampoco es incompatible con la imposición al sujeto infractor de medidas sancionadoras accesorias o especiales u otra serie de restricciones en sus derechos que no tengan carácter sancionador, entre las que cabe citar: la paralización de los trabajos acordada en caso de riesgo grave o inminente para la seguridad y salud de los trabajadores, el cumplimiento de las actas de requerimiento de subsanación formuladas por la Inspección de Trabajo, la exigencia de las deudas frente a la Seguridad Social en materia de cotizaciones con el correspondiente incremento por mora o -cómo no- la imposición del recargo de prestaciones de Seguridad Social ${ }^{44}$.

\section{Principio de culpabilidad}

Cuenta con distinta aplicación en el ámbito penal y en el sancionador administrativo. Para el primero son delitos o faltas, las acciones u omisiones dolosas o culposas penadas por la ley, de forma tal que no hay pena sin dolo o culpa, puesto que la culpabilidad se integra en la misma configuración del delito o falta en virtud del conocido aforismo "nulla poena sine culpa". Por el contrario, en el segundo, no suele advertirse la presencia de tal elemento configurador subjetivo. Así se puede observar cómo en la LISOS la culpabilidad no es componente esencial en la configuración legal de la infracción administrativa, de forma que, en este ámbito se prescinde implícita, aunque inequívocamente, de tal requisito, quedando relegada la mencionada culpabilidad a un mero elemento modal o de graduación de la sanción administrativa ${ }^{45}$.

Bajo tales premisas, la LISOS configura de forma mayoritaria las infracciones como de peligro abstracto, donde no existe ni un daño real, ni un riesgo concreto sino

42 Orcaray Reviriego, J.: "El principio non bis in idem y su reflejo en el procedimiento sancionador por infracciones del orden social”, Justicia Laboral, núm. 29, 2007, pp. 11 y ss.

43 Monereo Pérez, J.L. y Fernández Avilés, J.A.: "El Derecho Administrativo sancionador del trabajo: principios y rasgos constitutivos”, cit., p. 33.

44 Cruz Villalón, J.: "Principios constitucionales del ejercicio de la potestad sancionadora en el orden social”, Justicia Laboral, número extraordinario, 2001, pp. 23 y ss.

45 Blasco Pellicer, A.: Sanciones administrativas del orden social, cit., p. 32. 
únicamente estadístico o hipotético ${ }^{46}$; y dentro de ellas se encuentra generalizada, además, la tipificación de infracciones de mera conducta o de omisión de tales obligaciones formales, siendo una excepción las infracciones de resultado ${ }^{47}$. Esto tiene una muestra evidente en las infracciones en materia de prevención de riesgos laborales, cuya característica principal radica precisamente en que el tipo administrativo, que en general pauta incumplimientos de obligaciones del empleador de actividad o de medios, se perfecciona exclusivamente con la mera inobservancia de la norma de seguridad y salud en el trabajo correspondiente, con entera independencia de que la conducta infractora produzca o no resultados dañosos o perjuicios materiales en el trabajador y con autonomía respecto a las responsabilidades que pudieran concurrir en los otros órdenes jurisdiccionales, civil, penal e incluso laboral ${ }^{48}$.

En cualquier caso, la imputación de la infracción puede verse dificultada cuando no es exclusiva de un sujeto único, sino que en su comisión intervienen una pluralidad de responsables (coautoría, incumplimiento de coobligados, deber exigible a un sujeto de prevenir la infracción cometida por otros... $)^{49}$. En principio, en los casos de autoría conjunta la solución más razonable es imponer a cada persona infractora una sanción independiente, pero, en determinadas ocasiones, el legislador opta por establecer una responsabilidad solidaria, que permite a la Administración incoar un expediente sancionador frente a todos los presuntos responsables, y deducida la misma, reclamará el pago de una única sanción a uno, varios o todos ellos, no en vano "las específicas relaciones inter-empresariales que subyacen en muchos casos van a determinar que el garantismo que impregna este ámbito jurídico reconozca tal sistema de responsabilidad a los sujetos implicados" ${ }^{50}$.

Más discutible resulta la posibilidad de expandir la responsabilidad administrativa sancionadora por incumplimiento de las obligaciones que conforme a la norma sustantiva corresponden a otro sujeto. Es precisamente en el ámbito de la prevención de riesgos laborales donde aparecen previsiones sobre la obligación genérica de vigilancia y control tanto de las condiciones de trabajo como del comportamiento y actitud de los trabajadores en la realización de su actividad profesional, así como de la presencia de otras empresas en el entorno laboral de un determinado empresario, lo cual le obliga a coordinar las actividades preventivas, quedando convertido a veces en responsable subsidiario de los hechos infractores cometidos por otros o participando de la responsabilidad solidaria en que puedan incurrir varios empresarios obli-

46 Pemán Gavín, I.: El sistema sancionador español. Hacia una teoría general de las infracciones y sanciones administrativas, Barcelona (Cedecs), 2000, pp. 296-297.

47 De Palma del Teso, A.: El principio de culpabilidad en el Derecho Administrativo Sancionador, Madrid (Tecnos), 1996, p. 138.

48 Camas Roda, F.: "Las infracciones y sanciones administrativas del empresario en el orden social", cit., p. 11.

49 García Piqueras, M.: "La potestad sancionadora de la Administración en el orden social: apuntes sobre una construcción jurisprudencial”, Revista Trabajo y Seguridad Social, núm. 6, 1992, pp. 7 y ss.

50 Monereo Pérez, J.L. y Fernández Avilés, J.A.: “El Derecho Administrativo sancionador del traba210 jo: principios y rasgos constitutivos”, cit., p. 23. En la jurisprudencia, por todas, SSTS, Cont-Admtivo, 25 
gados a cumplir con el deber de vigilancia ${ }^{51}$. Evidentemente, la compatibilidad de esta técnica de responsabilidad con el principio constitucional de culpabilidad e imputabilidad es muy dudosa en los supuestos en que se contempla como sujeto activo a alguien que no está obligado por el deber infringido y al que tampoco se le impone un deber in vigilando del cumplimiento de tal obligación por parte del obligado por la normativa sustantiva (tal y como sucede, por ejemplo, en el art. 23.2 LISOS) ${ }^{52}$.

En fin, la admisión de la persona jurídica o la comunidad de bienes como sujeto activo de las infracciones administrativas plantea la especial problemática de la imputación subjetiva o intencional, al no coincidir el sujeto autor material del ilícito con el responsable legal. En efecto, la referencia a las organizaciones transpersonales o impersonales como posibles sujetos responsables administrativamente conlleva el problema de su compatibilidad con la exigencia de culpabilidad en orden a la imputación de infracciones y a la imposición de sanciones. Conforme a la doctrina del Tribunal Constitucional, el principio de personalidad de la sanción no impide que el Derecho Administrativo sancionador admita la responsabilidad directa de las personas jurídicas, sin que ello implique, al tiempo, la supresión del elemento subjetivo de culpa, sino simplemente que ese principio se ha de aplicar necesariamente de forma distinta a como se hace respecto de las personas físicas ${ }^{53}$. Es más, dado que las sanciones administrativas en ningún caso pueden consistir en penas privativas de libertad, el principio de culpabilidad se atenúa de modo automático en el marco aquí analizado ${ }^{54}$.

\section{Principio de proporcionalidad}

Como parámetro de mensurabilidad, aplicado al ejercicio de potestades públicas limitativas de la actividad de los ciudadanos y, concretamente, en materia sancionadora, implica una correlación adecuada entre la sanción susceptible de ser impuesta y la infracción cometida, atendiendo fundamentalmente a la gravedad de ésta y al grado de culpabilidad del sujeto infractor ${ }^{55}$. Con ello se consigue un mejor ajuste -un engarce racional- entre la consecuencia punitiva prevista en la norma y el incumplimiento tipificado en ella, a fin de menoscabar lo menos posible (sólo en su justa medida) los derechos del sujeto sancionado ${ }^{56}$.

51 Álvarez Cuesta, H.: “Los intentos legislativos por cambiar la descorazonadora realidad preventiva en las contratas y subcontratas”, en AA.VV. (Fernández Domínguez, J.J., Dir.): La prevención de riesgos laborales y las nuevas formas de organización empresarial y del trabajo, Valladolid (Junta de Castilla y León), 2007, pp. 49 y ss.

52 Monereo Pérez, J.L. y Fernández Avilés, J.A.: “El Derecho Administrativo sancionador del trabajo: principios y rasgos constitutivos", cit., p. 23.

53 STCo 246/1991, de 19 de diciembre. En el mismo sentido, STS, Cont-Admtivo, 19 diciembre 1994 (Ar. 9800).

54 Quintero Olivares, G.: “La autotutela, los límites al poder sancionador de la Administración Pública y los principios inspiradores del Derecho Penal”, Revista de Administración Pública, núm. 126, 1991, pp. 253 y ss.

55 STCo 65/1986, de 22 de mayo.

56 López González, I.: El principio general de proporcionalidad en el Derecho Administrativo, Sevilla (Instituto García Oviedo), 1988, pp. 28 y ss. 
En desarrollo de estas premisas, la LISOS ha consagrado este principio en sus arts. 39, 40 y 41, de modo que, una vez ha sido calificada la infracción cometida como leve, grave o muy grave, el principio de proporcionalidad se debe aplicar a través de la consideración de diversos criterios de graduación de las sanciones (en grado mínimo, medio y máximo) dentro de cada una de aquellas calificaciones ${ }^{57}$.

Uno de los aspectos más peculiares del juego de este principio en el orden social es que los criterios a utilizar para graduar las sanciones, resultan diferentes en función de si las infracciones administrativas corresponden, de una parte, al ordenamiento laboral y de Seguridad Social, o al ámbito de prevención de riesgos, de otra ${ }^{58}$. Así, mientras, de forma general, el art. 39.2 LISOS considera como criterios de graduación la existencia de intencionalidad o reiteración, los perjuicios causados y cantidad defraudada con la infracción, el fraude o connivencia, el incumplimiento de las advertencias previas y requerimientos de la Inspección, la cifra de negocios de la empresa, o el número de trabajadores o de beneficiarios afectados en su caso ${ }^{59}$; conforme al art. 39.3 LISOS, la imposición de las sanciones en materia de prevención de riesgos laborales en uno de los tres grados mencionados ha de hacerse con arreglo a los siguientes criterios legales: la peligrosidad de las actividades desarrolladas en la empresa o centro de trabajo, la permanencia o transitoriedad de los riesgos inherentes a dichas actividades, la gravedad de los daños producidos o que hubieran podido producirse por la ausencia o deficiencia de las medidas preventivas necesarias, el número de trabajadores afectados, las medidas o elementos de protección colectiva o individual adoptadas por el empresario y las instrucciones impartidas en orden a la prevención de tales riesgos, el incumplimiento de las advertencias o requerimientos previos de la Inspección, la inobservancia de las propuestas realizadas por los servicios de prevención, los delegados de prevención o el comité de seguridad y salud de la empresa para la corrección de las deficiencias legales existentes, y la conducta general seguida por el empresario en orden a la estricta observancia de las normas en materia de prevención de riesgos laborales ${ }^{60}$.

\section{SUJETOS RESPONSABLES}

El art. 1 LISOS define las infracciones administrativas en el orden social como "las acciones y omisiones de los distintos sujetos responsables tipificadas y sancionadas en la presente Ley y en las leyes del orden social". El aspecto personal de estas infracciones, relativo al sujeto infractor, delimita su campo de aplicación ${ }^{61}$. Tal mención de

57 Mercader Uguina, J.R. y Tolosa Tribiño, C.: Derecho Administrativo Laboral, Valencia (Tirant Lo Blanch), 2000, p. 579.

58 Sánchez-Terán Hernández, J.M.: Los criterios de graduación de las sanciones administrativas en el orden social, Valladolid (Lex Nova), pp. 43 y ss.

59 Sobre tales criterios, STS, Cont-Admtivo, 19 abril 2004 (RJ 4049).

60 Camas Roda, F.: "Las infracciones y sanciones administrativas del empresario en el orden social", cit., p. 14 .

61 Sempere Navarro, A.V. y Martín Jiménez, R.: “Disposiciones generales”, en AA.VV. (Sempere $212 \quad$ zavarro, A.V., Coord.): 
los "distintos sujetos infractores" se amplía en el art. 2, a tenor de una doble técnica: a) Primero, elaborando una definición general de sujeto responsable, en alusión a "personas físicas o jurídicas y las comunidades de bienes que incurran en las acciones u omisiones tipificadas como infracción en la LISOS”. b) Segundo, incorporando una lista precisa, a modo de declaración constitutiva (hasta trece enunciados), de sujetos responsables según la norma laboral o de Seguridad Social infringida ${ }^{62}$.

La razón de tan detallada identificación responde a la necesidad de garantizar el principio de seguridad jurídica en materia sancionadora, de forma que sólo los mencionados en el art. 2 LISOS, y no otros, serán sancionados como consecuencia del incumplimiento de las obligaciones en que hayan incurrido en los ámbitos estableci$\operatorname{dos}^{63}$. Un repaso de tal elenco obliga a detallar -siquiera brevemente-las siguientes circunstancias:

1. El primer sujeto que aparece mencionado es el empresario, que inicia la lista como responsable en materia laboral. Conforme a la LISOS, en el marco de la relación jurídico-laboral, la potestad sancionadora de la Administración recae exclusivamente sobre una de las partes de la relación contractual: la empresa ${ }^{64}$. En consecuencia, esta Ley mantiene la consideración histórica del titular de la organización productiva como posible y único infractor del régimen de derechos y deberes contractuales de carácter laboral, asentado en el fundamento de que es aquél, en cuanto titular y responsable de la empresa, quien ha de velar por el cumplimiento de la normativa laboral en los establecimientos sometidos a su control. Así pues, se adopta como hipótesis de partida la idea de que el Derecho del Trabajo es un ordenamiento básicamente instituido para la tutela del trabajador ${ }^{65}$.

No cabe ninguna duda de que para perfilar la noción de empresario es necesario acudir a lo previsto en el art. 1.2 ET, que refiere dicha condición a quien recibe la prestación de servicios (siendo persona física, jurídica o comunidad de bienes) bajo las notas de voluntariedad, personalidad, remuneración, ajenidad y dependencia ${ }^{66}$. Conforme a estas pautas caracterizadoras, para ser empresario laboral no es necesario llevar a cabo una actividad económica o productiva, ni tampoco que exista una organización en forma de empresa, ni que ostente una titularidad dominical de los medios de producción, ni que persiga tampoco la obtención de un lucro ${ }^{67}$. Todo ello sin olvi-

62 Cámara Botía, A.: “La potestad sancionadora de la Administración en el orden social: cuestiones generales", cit., p. 55 .

63 García Blasco, J.: "Art. 2", en AA.VV.: Infracciones y sanciones en materia laboral. Un comentario a la Ley 8/1998, de 7 de abril, Madrid (Civitas), 1989, p. 57.

64 Camas Roda, F.: “Las infracciones y sanciones administrativas del empresario en el orden social", cit., p. 20.

65 Sirva la referencia al estudio de Montoya Melgar, A.: "El procedimiento de imposición de sanciones por infracción de la legislación laboral”, Revista Española de Derecho del Trabajo, núm. 129, 1969, p. 36.

66 SSTS, Social, 7 octubre 1987 (RJ 6937) y 3 mayo 1990 (RJ 3946).

67 Entre muchas, SSTS, Social, 15 julio 1996 (RJ 5990) y 31 diciembre 1997 (RJ 9867). 
dar que la LISOS sigue considerando como responsabilidad personal la del empresario individual, optando, por otra parte, cuando se trata de una persona jurídica o de una comunidad de bienes, por la responsabilidad de la propia entidad mercantil ${ }^{68}$, sin que de esta forma, hayan sido acogidas las tesis, que, de lege ferenda, apuestan por un reparto de responsabilidades entre el empresario y sus delegados, o entre la sociedad y sus directivos ${ }^{69}$.

Asimismo, constatada la concurrencia de las notas antes señaladas, es indiferente que el empresario sea un sujeto de Derecho Privado o un sujeto de Derecho Público. Ahora bien, aun cuando la Administración, como parte de las relaciones laborales, estaría sujeta a las "mismas reglas jurídicas que los demás empleadores"70, surge de inmediato un problema derivado: los Entes gubernativos no pueden ser sujetos activos de las infracciones, debido a las dificultades de admitir la autosanción desde la perspectiva ontológica de la unidad del poder ejecutivo ${ }^{71}$. Así, una de las peculiaridades de la aplicación de la LPRL a las Administraciones Públicas viene constituida por la previsión en el art. 45.1 a favor de un procedimiento sancionador especial que culmina no con la imposición de sanciones pecuniarias, sino con la obligación de realizar otras medidas correctoras de los correspondientes incumplimientos. De este modo, el art. 42.4 LISOS afirma que la corrección de las infracciones en materia de prevención de riesgos laborales "en el ámbito de las Administraciones Públicas" se sujetará al procedimiento y normas de desarrollo del art. 45 LPRL (esto es, el Real Decreto 707/2002, de 19 de julio, modificado posteriormente por el Real Decreto 464/2003, de 25 de abril $)^{72}$, que simplemente regulan un sistema de requerimientos para subsanar los posibles incumplimientos ${ }^{73}$.

En fin y a efectos meramente aclaratorios, cuando se habla de empresario responsable en materia laboral, se está haciendo referencia a las infracciones recogidas en los arts. 5 a 19 bis LISOS, singularmente las siguientes: a) Infracciones en materia de relaciones laborales, tanto individuales como colectivas (arts. 6 a 8); en materia de derechos de información y consulta de los trabajadores en las empresas y grupos de empresas de dimensión comunitaria (art. 9); de las obligaciones relativas a las condiciones de trabajo de los trabajadores desplazados temporalmente a España en el

68 Páramo Montero, P.: “El empresario como sujeto imputable en la Ley de Infracciones y sanciones del orden social: especial referencia a las entidades desprovistas de personalidad jurídica”, Actualidad Laboral, T. I, 1998, pp. 219 y ss.

69 Páramo Montero, P.: "Puntos conflictivos en torno al poder sancionador de la Administración Laboral”, Relaciones Laborales, núm. 11, 2001, pp. 39 y ss.

70 STCo 206/1987, de 21 de diciembre.

71 Casas Baamonde, M.E.: “Derecho Público y salud laboral: el régimen jurídico sancionador”, en AA.VV. (Casas Baamonde, M.E.; Palomeque López, C. y Valdés Dal-Re, F., Coords.): Seguridad y salud en el trabajo, Madrid (La Ley), 1997, pp. 176 y ss.

72 Mercader Uguina, J.R. y Tolosa Tribiño, C.: “Las especialidades de la responsabilidad de las Administraciones Públicas en materia de prevención de riesgos laborales: ¿del buen uso a la lentitud?”, Relaciones Laborales, T. II, 2002, pp. 1095 y ss.

73 Montoya Melgar, A. y Pizá Granados, J.: Curso de seguridad y salud en el trabajo, 2. ${ }^{\text {a }}$ edición, 
marco de una prestación transnacional (art. 10); en materia de derechos de información, consulta y participación de los trabajadores en las sociedades anónimas y sociedades cooperativas europeas (art. 10 bis). b) Infracciones en materia de prevención de riesgos laborales (arts. 11 a 13). c) Infracciones en materia de empleo (arts. 14 a 17). d) Infracciones en materia de empresas de trabajo temporal y empresas usuarias (arts. 18 y 19) y e) Infracciones en materia de empresas de inserción (art. 19 bis).

2. En relación con las contravenciones producidas respecto de las normas de Seguridad Social, el art. 2.2 LISOS establece dos colectivos de sujetos responsables ${ }^{74}$ : por un lado, los responsables del incumplimiento de las obligaciones en el ámbito de las relaciones de Seguridad Social, que serían los enumerados en la primera parte del artículo (empresarios, trabajadores por cuenta propia o ajena o asimilados, perceptores y solicitantes de las prestaciones de Seguridad Social, mutuas de accidentes de trabajo y enfermedades profesionales y demás entidades colaboradoras en la gestión); de otro, los responsables de la trasgresión de los deberes de carácter informativo (entidades o empresas responsables de la gestión de prestaciones en cuanto a sus obligaciones en relación con el registro de prestaciones sociales públicas y demás sujetos obligados a facilitar información de trascendencia recaudatoria en materia de Seguridad Social), referidos en el último inciso del precepto ${ }^{75}$.

La primera parte de la lista corre casi paralela a la clasificación de las infracciones en materia de Seguridad Social establecida en el capítulo III LISOS: a) Infracciones de los empresarios, trabajadores por cuenta propia y asimilados (arts. 21 a 23); b) Infracciones de los trabajadores o asimilados (arts. 24 a 16); c) Infracciones de las mutuas de accidentes de trabajo y enfermedades profesionales de la Seguridad Social (arts. 27 a 29); d) Infracciones de las empresas que colaboran voluntariamente en la gestión (arts. 30 a 32$)^{76}$.

La segunda parte del precepto obliga a acudir a lo previsto en el art. 8 Real Decreto 397/1996, de 1 de marzo, que especifica quiénes deben cumplir con las obligaciones establecidas en relación con el registro de prestaciones sociales públicas: a) Los órganos competentes de la Administración General del Estado, así como las entidades de derecho público con personalidad jurídica propia vinculadas o dependientes de la misma, que tengan a su cargo el reconocimiento, el mantenimiento o el abono de las prestaciones sociales públicas. b) Los órganos competentes de las Administraciones de las Comunidades Autónomas y de las Corporaciones Locales, así como las Entidades de Derecho Público, con personalidad jurídica propia, vinculadas

74 Blasco Lahoz, J.F.: “Las infracciones y sanciones en materia de Seguridad Social tras la publicación del nuevo texto refundido de la Ley de Infracciones y Sanciones en el orden social”, Actualidad Laboral, T. I, 2001, pp. 29 y ss.

75 Meléndez Morillo Velarde, L.: “Los sujetos responsables en la Ley de Infracciones y Sanciones del Orden Social”, Revista del Ministerio de Trabajo y Seguridad Social, núm. 78, 2008, p. 107.

76 Cámara Botía, A.: “La potestad sancionadora de la Administración en el orden social: cuestiones generales", cit., p. 58. 
o dependientes de las mismas que reconozcan, mantengan o abonen, en todo o en parte, las prestaciones sociales públicas. c) Las mutualidades, montepíos, entidades de previsión social, entidades sustitutorias de las entidades gestoras del sistema de la Seguridad Social, Mutuas y, en general, cualesquiera otros entes que reconozcan, mantengan o abonen prestaciones sociales públicas que se financien, en todo o en parte, con recursos públicos. d) Y las empresas o sociedades con participación mayoritaria, directa o indirectamente en su capital, del Estado, Comunidades Autónomas, Corporaciones Locales u organismos de uno y otras, que reconozcan, mantengan y abonen prestaciones públicas ${ }^{77}$.

3. En materia de colocación, fomento de empleo y formación, son los empresarios, los trabajadores, los solicitantes de subvenciones públicas y, en general, las personas físicas o jurídicas, los sujetos responsables de la infracción de las normas correspondientes a tales sectores (art. 2.3 LISOS). Por su parte, el art. 2.7 LISOS se refiere a las agencias de colocación "respecto de las obligaciones que se establecen en su legislación específica... sin perjuicio de lo establecido en otros números de este artículo". Con ello, una vez más, se traslada la pertinente clasificación, de modo que las infracciones en el marco del empleo se estructuran en: a) Infracciones de los empresarios, de las agencias de colocación y de los beneficiarios de ayudas y subvenciones en materia de empleo, ayudas de fomento del empleo en general y formación profesional ocupacional y continua (arts. 14 a 16 LISOS) ${ }^{78}$; b) Infracciones de los trabajadores por cuenta ajena y propia (art. 17 LISOS) 79 .

4. En materia de movimientos migratorios, el art. 2.4 LISOS enumera como sujetos responsables a los transportistas, agentes, consignatarios, representantes, trabajadores $y$, en general, las personas físicas o jurídicas que intervengan en los mismos. La LISOS pretende así proteger a los trabajadores emigrantes mediante la imputación de responsabilidad a todos los que pueden participar, de forma directa o indirecta, en la organización de movimientos migratorios, en el reclutamiento o contratación y en las condiciones de trabajo ofertadas para emigrar (arts. 33 a 36 LISOS) $)^{80}$.

5. Conforme a lo previsto en el art. 2.5 LISOS, los empresarios y los trabajadores por cuenta propia pueden incurrir en la responsabilidad derivada del incumplimiento de las normas sobre el trabajo de extranjeros, en clara remisión a lo dispuesto en el art. 37 LISOS, que tipifica tanto las infracciones como los sujetos responsables. A estos efectos, el art. 37.3 añade a una persona más a las listadas en el art. 2.5, que

77 Meléndez Morillo-Verlarde, L.: “Los sujetos responsables en la Ley de Infracciones y Sanciones en el Orden Social", cit., p. 106.

78 Sirva de ejemplo la STS, Cont-Admtivo, 11 febrero 2003 (RJ 2018).

79 Cámara Botía, A.: “La potestad sancionadora de la Administración en el orden social: cuestiones generales", cit., p. 59.

80 Camas Roda, F.: “La dispersión de las infracciones laborales relativas al trabajo de extranjeros: análisis de la compatibilidad entre las sanciones derivadas de la comisión infracciones previstas en al Ley de Infracciones y Sanciones del Orden Social y en la Ley Orgánica de Extranjería”, cit., p. 193. 
puede ser considerada imputable en materia de trabajo de extranjeros. Se trata de "las personas físicas o jurídicas que promuevan, medien o amparen el trabajo de los no comunitarios en España sin el preceptivo permiso de trabajo", quedando incluidos no sólo los empresarios laborales, sino cualquier individuo que participe en la conducta recogida en el tipo ${ }^{81}$. Todo ello sin olvidar cómo las infracciones en materia de extranjería se regulan también en los arts. 52 a 54 Ley Orgánica 4/2000, de 11 de enero, sobre derechos y libertades de los extranjeros en España y su inserción social ${ }^{82}$. Por tal razón, los sujetos identificados en el art. 2.5 LISOS no sólo son responsables de las infracciones tipificadas en la propia LISOS, sino también de las previstas en la mencionada Ley Orgánica 4/200083.

6. Sobre la propia cooperativa, o sobre sus órganos de gobierno, recae la responsabilidad de las infracciones tipificadas en el art. 38 LISOS, referidas a las cometidas tanto respecto a sus socios trabajadores como a los socios de trabajo (art. 2.6 LISOS) ${ }^{84}$.

7. Las empresas de trabajo temporal y las empresas usuarias son responsables del incumplimiento de las obligaciones establecidas en su legislación específica (Ley 14/1994, de 1 de junio) y en la de prevención de riesgos laborales (art. 2.7 LISOS). El art. 18 LISOS tipifica las infracciones de las empresas de trabajo temporal y el art. 19 LISOS las de las empresas usuarias ${ }^{85}$.

Es importante tener en cuenta, no obstante, que ambas realidades empresariales, desde el momento en que cuentan con sus propios trabajadores dependientes, son sujetos infractores de la LISOS como cualquier otro empresario (en materia de relaciones laborales, empleo, Seguridad Social, emigración...). Ahora bien, además de las infracciones que puede cometer cualquier empleador (según el amplio concepto del art. 1.2 ET utilizado por el art. 2.1 LISOS), las empresas de trabajo temporal y las empresas usuarias pueden ser sujetos responsables de determinadas infracciones

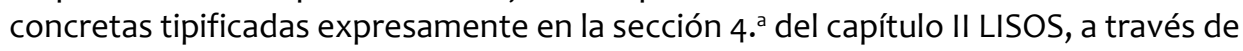

81 Cavas Martínez, F.: “Infracciones y sanciones en materia de movimientos migratorios y trabajo de extranjeros”, en AA.VV. (Cavas Martínez, F. y Luján Alcaraz, J., Dirs.): Infracciones y sanciones en el orden social. Régimen jurídico, cit., pp. 402 y ss.

82 Camas Roda, F.: “La dispersión de las infracciones laborales relativas al trabajo de extranjeros: análisis de la compatibilidad entre las sanciones derivadas de la comisión de las infracciones previstas en la Ley de Infracciones y Sanciones del Orden Social y en la Ley Orgánica de Extranjería”, cit., pp. 191 y ss.

83 Purcalla Bonilla, M.A.: "La regulación de los derechos y libertades de los extranjeros en España y su integración social: la reforma de la Ley Orgánica 4/2000, de 11 de enero, a través de la Ley Orgánica 8/2000, de 22 de diciembre”, Tribuna Social, núm. 122, 2001, p. 49 o Charro Baena, P.: “El trabajo de los extranjeros en España: una lectura desde el ordenamiento laboral", Revista del Ministerio de Trabajo y Asuntos Sociales, núm. 63, 2006, p. 18.

84 Luján Alcaraz, J. y Selma Penalva, A.: "Infracciones y sanciones en materia de sociedades cooperativas”, en AA.VV. (Cavas Martínez, F. y Luján Alcaraz, J., Dirs.): Infracciones y sanciones en el orden social. Régimen jurídico, cit., p. 413.

85 Rodríguez-Piñero Royo, M.: Las empresas de trabajo temporal en España, Valencia (Tirant Lo Blanch), 1994, pp. 113 y ss. 
las cuales se pretende garantizar la correcta aplicación de las normas específicas que impone la Ley 14/1994 y que regulan la cesión lícita de trabajadores a través de este tipo de entidades empresariales. Hay que tener en cuenta, asimismo, que tal y como la propia Ley 14/1994 (art. 25.1) se ocupa de aclarar, cuando se trate de una empresa de trabajo temporal que realice una actividad transnacional, además de las infracciones en materia de empresas de trabajo temporal y empresas usuarias (sección $4 .{ }^{\text {a }}$ del capítulo II) tipificadas en los arts. 18 y 19 LISOS, también puede ser sujeto activo de las infracciones relativas a las condiciones de trabajo de los trabajadores desplazados temporalmente a España en el marco de una prestación transnacional de servicios, enumeradas en el art. 10 (subsección 3. ${ }^{a}$ de la sección 2. ${ }^{a}$ del capítulo II LISOS) ${ }^{86}$.

8. En materia de prevención de riesgos laborales, se recoge un amplio elenco de sujetos, que conforme al art. 2 LISOS, pueden incurrir en responsabilidad ${ }^{87}$ :

a) Los empresarios titulares de centro de trabajo, los promotores y propietarios de obras y los trabajadores por cuenta propia (art. 2.8 LISOS), a los cuales procede añadir los contratistas y subcontratistas, pues, tras la aprobación de la Ley 32/2006, de 18 de octubre, reguladora de la Subcontratación en el sector de la Construcción, éstos también deben considerarse responsables respecto de los incumplimientos tipificados en los arts. 12, apartados 27 y 28, y 13, apartados 15 y 16 LISOS.

b) Las entidades especializadas que actúen como servicios de prevención ajenos a las empresas, las personas o entidades que desarrollen la actividad de auditoría del sistema de prevención de las empresas y las entidades acreditadas para desarrollar y certificar la formación en materia de prevención de riesgos laborales que incumplan las obligaciones establecidas en la normativa sobre dicha materia (art. 2.9 LISOS).

c) Las empresas de trabajo temporal y las empresas usuarias podrán ser sujetos responsables cada una de sus propias infracciones "en materia de prevención de riesgos laborales”, en los términos que concreta el art. 42.2 LISOS.

9. La relevancia que para la LISOS tienen las infracciones en materia de los derechos de información, consulta y participación de los trabajadores, se manifiesta a través de la garantía de su protección en dos ámbitos distintos y con la identificación de dos posibles responsables de las infracciones tipificadas. En primer lugar, el art. 2.10 LISOS se refiere a los responsables de la infracción en los centros de trabajo o de las empresas de dimensión comunitaria situadas en territorio español, quedando conferida la responsabilidad tanto a las personas físicas como jurídicas y a las comu-

86 Luján Alcaraz, J. y Selma Penalva, A.: "Infracciones y sanciones en materia de empresas de trabajo temporal y empresas usuarias”, en AA.VV (Cavas Martínez, F. y Luján Alcaraz, J., Dirs.): Infracciones y sanciones en el orden social. Régimen jurídico, cit., p. 286.

87 Luján Alcaraz, J. y Selma Penalva, A.: "Infracciones y sanciones en materia de prevención de 218 den social. Régimen jurídico, cit., p. 174. 
nidades de bienes que ostenten la titularidad de los centros de trabajo o de las empresas. El principio de territorialidad rector de la aplicación de las normas sancionadoras determina que para la viabilidad de posibles sanciones tales empresas o grupos de empresas han de estar radicadas en territorio español. Por lo que respecta a las agrupaciones empresariales, ello supone un levantamiento ex lege de la personalidad jurídica, que tiende a asegurar la efectividad de las posibles sanciones en esta materia, dada la ausencia de una "normación" e identificación de estos entes sin personalidad con carácter general a efectos sancionadores ${ }^{88}$.

En segundo término, el art. 2.12 LISOS identifica como posibles responsables a un amplio elenco de sujetos: a) las sociedades europeas y las sociedades cooperativas europeas con domicilio social en España; b) las sociedades, entidades jurídicas y, en su caso, las personas físicas domiciliadas en España que participen directamente en la constitución de una sociedad europea o de una sociedad cooperativa europea; c) las personas físicas o jurídicas o comunidades de bienes titulares de los centros de trabajo situados en España de las sociedades europeas y de las sociedades cooperativas europeas y de sus empresas filiales y de las sociedades y entidades jurídicas participantes, cualquiera que sea el Estado miembro en que se encuentren domiciliadas ${ }^{89}$.

10. Responsables de los incumplimientos producidos en relación con la prestación de servicios de carácter transnacional, son los empresarios incluidos en el ámbito de aplicación de la normativa legal que regula el desplazamiento de trabajadores en el marco de una prestación de servicios (art. 2.11 LISOS): A estos efectos, la Ley 45/1999, de 29 de noviembre, identifica como tales "las empresas establecidas en un Estado miembro de la Unión Europea o de un Estado signatario del Acuerdo sobre el Espacio Económico Europeo que desplacen temporalmente a sus trabajadores a España en el marco de una prestación de servicios transnacional, con exclusión de las empresas de marina mercante respecto de su personal navegante" (art. 1.2). De conformidad con este precepto, el ius puniendi de la Administración laboral española se extiende a empresas situadas en el extranjero, que también son destinatarias de normas nacionales destinadas a garantizar la aplicación de las prescripciones españolas de orden público en materia laboral a los trabajadores desplazados por tales empresas a nuestro país para llevar a cabo una prestación de servicios. Ello comporta "un reforzamiento del principio de territorialidad, y una mayor garantía de que el desplazamiento temporal de trabajadores en el marco de una prestación transnacional de servicios no implica conculcación de las normas laborales de ius cogens vigentes en nuestro país"90.

88 Monereo Pérez, J.L. y Fernández Avilés, J.A.: "Sujetos responsables de la infracción”, en AA.VV (García Blasco, J. y Monereo Pérez, J.L., Dirs.): Comentario sistemático al texto refundido de la Ley de Infracciones y Sanciones en el orden social y normas concordantes, cit., p. 7.

89 Meléndez Morillo-Velarde, L.: “Los sujetos responsables en la Ley de Infracciones y Sanciones en el orden social", cit., p. 118. p. 78.

90 Monereo Pérez, J.L. y Fernández Avilés, J.A.: "Sujetos responsables de la infracción”, cit., 
11. La aprobación de la Ley 44/2007, de 13 diciembre, de Empresas de Inserción, ha tenido su natural repercusión en materia sancionadora: el nuevo art. 2.13 LISOS incluye a estas empresas dentro de la lista de sujetos responsables y el nuevo art. 19 bis LISOS tipifica las infracciones correspondientes ${ }^{91}$.

\section{INFRACCIONES}

El principio de legalidad exigido en el régimen sancionador administrativo, no se desenvuelve exclusivamente en la vertiente formal de la reserva legal que dé certeza y seguridad jurídica a la preexistente exigencia del ilícito que se trate de enjuiciar, sino también presenta una faceta material consistente en la exigencia de que sólo sean sancionables aquellas conductas previstas con la precisión necesaria para evitar cualquier incertidumbre en su aplicación. Se erige así la tipicidad como elemento objetivo determinante de las sanciones punibles, cuyo desarrollo admite dos pasos sucesivos, primero configurando en la ley las conductas que han de recibir la consideración de infracción administrativa y, posteriormente, atribuyendo a cada una de ellas la sanción que corresponda ${ }^{92}$.

\section{Graduación}

Sin pretender realizar un repaso de la identificación de los comportamientos constitutivos de infracción laboral, sí cabe poner de manifiesto que dichas conductas pueden y deben ser objeto de graduación, con arreglo "a la naturaleza del deber infringido y la entidad del derecho afectado" (art. 1.3 LISOS)93. Uno pone en conexión el incumplimiento normativo con los bienes jurídico-públicos que se hallan en la base de su protección, mientras que el otro atiende más bien al derecho subjetivo (individual o colectivo) lesionado por la conducta típica. La norma enlaza así las vertientes objetiva y subjetiva del Derecho cuya garantía de ambas es un complemento recípro$\mathrm{CO}^{94}$. Y es que la tutela sancionadora no sólo consiste en la defensa y protección de los intereses generales, sino también de los intereses particulares, en los casos en que el ejercicio de la potestad corrige los desajustes sobre la norma de determinadas conductas que afectan a derechos individuales (aunque ello no implique la restitución o reparación del daño causado al personal perjudicado, no en vano para ello hay otros mecanismos jurídicos de tutela). Si bien la potestad sancionadora del poder público siempre debe ejercerse por razones de interés general, de manera indirecta ello también contribuye a la garantía de los derechos de los particulares por sus efectos disuasorios de conductas ilícitas ${ }^{95}$.

91 Vallecillo Gámez, M.R. y Molina Navarrete, C.: Empresas de inserción y mercados de trabajo inclusivos. Nuevo marco regulador y modelo de gestión, Granada (Comares), 2008, pp. 53 y ss.

92 AA.VV (Sempere Navarro, A.V., Coord.): Derecho Sancionador Público del Trabajo, Madrid (Colex), 2001, p. 318.

93 STS, Cont-Admtivo, 27 octubre 2003 (RJ 82).

94 Salinas Molina, F.: “Infracciones y sanciones en el orden social: derechos y garantías materiales y procedimentales”, Información Laboral (Jurisprudencia), núm. 3, 1999, pp. 4997 y ss.

95 Monereo Pérez, J.L. y Fernández Avilés, J.A.: “Infracciones en el orden social”, cit., p. 62. 
La clasificación en grados responde al principio de proporcionalidad que debe regir en el Derecho Administrativo Sancionador, de modo que: 1) Las infracciones leves atienden a la escasa entidad de los deberes incumplidos o de los derechos violados, o que el resultado de la infracción no produzca un perjuicio gravoso. 2) Las graves constituyen el módulo medio, integrado por aquellos tipos capaces de reflejar una entidad suficiente para su consideración como tales. 3) Las muy graves, como escalón extremo punitivo, representan la complementaria circunstancia de la gravedad con otro elemento que la potencia, como pudiera ser el resultado producido ${ }^{96}$.

En este sentido, la LISOS contempla como infracciones graves o muy graves las conductas que transgreden los derechos de mayor relevancia (libertad sindical, Seguridad Social, seguridad y salud de los trabajadores), mientras que las infracciones leves suelen venir referidas a incumplimientos de carácter formal, que no atentan a derechos fundamentales básicos ${ }^{97}$.

\section{Prescripción}

Una de las causas de extinción de la responsabilidad prevista legalmente se produce cuando no se ejercita la acción para descubrir y sancionar la infracción que se pudiera haber cometido, de modo que la prescripción de la infracción supone el transcurso de un plazo determinado tras la comisión de la misma sin que ésta haya sido perseguida. No cabe perder de vista, por tanto, que la potestad sancionadora solamente puede ejercerse válidamente dentro del límite temporal fijado por la ley, de manera que si la Administración impone una sanción cuando ya ha prescrito la infracción, la resolución administrativa estaría viciada de nulidad en lo que viene a ser una importante garantía del administrado frente a la pasividad de la primera ${ }^{98}$.

Con carácter general, el art. 4.1 LISOS señala que las infracciones del orden social referidas en el texto prescriben "a los tres años contados desde la fecha de la infracción”, duración que admite salvedades en atención a materias específicas. Si se trata de infracciones en materia de Seguridad Social, la prescripción tendrá lugar a los cuatro años (art. 4.2). En materia de prevención de riesgos laborales, las infracciones prescriben en plazos diferentes según el grado del ilícito: al año las leves, a los tres años las graves y a los cinco las muy graves, contados todos ellos desde la fecha de la comisión (art. 4.3). Una última excepción se produce en el caso de infracciones a la legislación de sociedades cooperativas, las cuales prescriben: si son leves, a los tres meses; si son graves, a los seis; y si son muy graves, al año (art. 4.4) ${ }^{99}$.

96 Blasco Pellicer, A.: Sanciones administrativas en el orden social, cit., pp. 79 y ss.

97 Sempere Navarro, A.V. y Martín Jiménez, R.: “Artículo 1. Infracciones en el orden social”, en AA.VV (Sempere Navarro, A.V., Coord.): Comentarios a la ley de Infracciones y Sanciones del orden social, Pamplona (Aranzadi), 2003, p. 50

98 SSTS, Cont-Admtivo, 22 octubre 1997 (Ar. 7542) y 24 marzo 2000 (Ar. 1565).

99 Sempere Navarro, A.V.y Martín Jiménez, R.: “Art. 4. Prescripción de las infracciones”, en AA.VV (Sempere Navarro, A.V., Coord.): Comentarios a la Ley de Infracciones y Sanciones del orden social, cit., pp. 84 y ss. 
En fin, los plazos de prescripción para la imposición de sanciones en el orden social se interrumpen por las causas legalmente establecidas (art. 7.2 Real Decreto 928/1998) ${ }^{100}$ : a) Acta de infracción debidamente notificada; b) Requerimiento u orden de paralización de la Inspección de Trabajo y Seguridad Social. c) Cualquier actuación administrativa realizada con conocimiento formal del responsable del pago conducente a la liquidación o recaudación de la deuda por cuotas a la Seguridad Social y, especialmente, por su reclamación administrativa mediante petición de deuda o acta de liquidación. d) Iniciación del procedimiento de oficio. e) Inicio de actuación administrativa con conocimiento formal del sujeto pasivo conducente a la comprobación de la infracción o de la deuda. f) Cualquier actuación del sujeto responsable que implique reconocimiento de los hechos constitutivos de la infracción o de la deuda. g) Interposición de reclamación o recurso de cualquier clase por parte de los afectados o sus representantes, bien a través de acciones administrativas o judiciales. h) Comunicación trasladando el tanto de culpa al órgano judicial competente o al Ministerio Fiscal, cuando las infracciones pudieran ser constitutivas de delito ${ }^{101}$.

\section{SANCIONES}

Definir lo que por sanción administrativa debe entenderse no resulta tarea fácil si tenemos en cuenta que nuestro ordenamiento jurídico no ofrece un concepto preciso, pero sí permite deducir como tal "cualquier mal infringido por la Administración a un administrado como consecuencia de una conducta ilegal, a resultas de un procedimiento administrativo y con una finalidad puramente represora" ${ }^{102}$.

\section{Clases}

Debiendo entender prohibidas las sanciones administrativas que impliquen privación de libertad (art. 25.3 CE), no cabe duda de que "la medida sancionadora administrativa por excelencia es la multa”, cuyo régimen jurídico en el orden social se fija en los arts. 39 y 40 LISOS, cumpliendo así con las exigencias del principio de legalidad, pues, como es sabido, las sanciones “en todo caso, estarán delimitadas por la ley” (art. 129 LRJAP).

Bajo la premisa del "no beneficio", es decir que la cuantía de la multa debe ser tal que la comisión de la infracción no resulte más beneficiosa para el infractor que el cumplimiento de las normas infringidas ${ }^{103}$, el art. 40 LISOS establece el montante de las sanciones pecuniarias, oportunamente actualizado, en las siguientes cantidades:

100 Beneyto Calabuig, D.: Las infracciones laborales y el procedimiento sancionador: análisis práctico y comentarios del texto refundido de la Ley sobre Infracciones y Sanciones en el orden social, Valencia (CISS), 2000, pp. 33 y ss.

101 Cámara Botía, A.: “La potestad sancionadora de la Administración en el orden social: cuestiones generales", cit., p. 77.

102 García de Enterría, E.: “El problema jurídico de las sanciones administrativas”, Revista Española de Derecho Administrativo, núm. 10, 1976, p. 399.

103 AA.VV (Sempere Navarro, A.V., Coord.): Derecho Sancionador Público del Trabajo, cit., p. 323. 
1. Infracciones en materia de relaciones laborales y empleo, en materia de Seguridad Social, de movimientos migratorios de extranjeros y por obstrucción: a) las leves, en su grado mínimo, de 60 a 125 euros; en su grado medio, de 126 a 310; y en su grado máximo, de 311 a 625. b) Las graves, en su grado mínimo, de 626 a 1.250; en su grado medio, de 1.251 a 3.125; y en su grado máximo, de 3.126 a 6.250. c) Las muy graves, en su grado mínimo, de 6.251 a 25.000; en su grado medio, de 25.001 a 100.005; y en su grado máximo, de 100.006 a 187.515 .

2. Infracciones en materia de prevención de riesgos laborales: a) Las leves, en su grado mínimo, de 40 a 405 euros; en su grado medio, de 406 a 815; y en su grado máximo, de 816 a 2.045. b) Las graves, en su grado mínimo, de 2.046 a 8.195; en su grado medio, de 8.196 a 20.490; y en su grado máximo, de 20.491 a 40.985. c) Las muy graves, en su grado mínimo, de 40.986 a 163.995; en su grado medio, de 163.956 a 409.890; y en su grado máximo, de 409.891 a 819.780.

3. Infracciones en materia de cooperativas: a) Las leves, de 375 a 755 euros. Las graves, de 756 a 3.790. c) Las muy graves, de 3.791 a 37.920.

Ahora bien, la sanción pecuniaria, "reservada a los empresarios, y en general, a otros sujetos que no tengan la condición de trabajadores o asimilados", no es el único tipo que cabe en este sector del ordenamiento ${ }^{104}$. Sin ánimo exhaustivo, cabe mencionar cómo en lo que concierne a la prevención de riesgos laborales, "cuando concurran circunstancias de especial gravedad", puede acordarse además "la suspensión de las actividades laborales por un tiempo determinado o, en caso de extremo, el cierre del centro de trabajo correspondiente", sin perjuicio de la continuidad del pago de los salarios (art. 53 LPRL).

Para determinadas infracciones muy graves en materia de empleo y protección por desempleo, pueden imponerse a los empresarios "sanciones accesorias" consistentes en la pérdida automática de las "ayudas, bonificaciones y, en general, los beneficios derivados de la aplicación de los programas de empleo" o en la exclusión del "acceso a tales beneficios por un período máximo de un año" (art. 46 LISOS) ${ }^{105}$.

En esta misma línea, el art. 45.4 de la Ley Orgánica 3/2007, de 22 de marzo, de Igualdad Efectiva entre Mujeres y Hombres, en concordancia con el art. 46 bis LISOS, faculta a la autoridad laboral a sustituir las sanciones accesorias impuestas en caso de infracciones por discriminación y acoso por la elaboración y aplicación de un "plan de igualdad" en los términos fijados por ella ${ }^{106}$.

104 Cámara Botía, A.: "Potestad sancionadora de la Administración en el orden social: cuestiones generales", cit., p. 60.

105 STS, Cont-Admtivo, 18 noviembre 2003 (RJ 57).

106 Castro Argüelles, M.A. y Rodríguez Cardo, I.A.: “Infracciones y sanciones en materia de igualdad en el ámbito de las relaciones laborales", Revista del Ministerio de Trabajo y Asuntos Sociales, núm. 78, 2008, pp. 255 y ss. 
En materia de Seguridad Social, con carácter accesorio se prevé la intervención temporal, remoción de sus órganos de gobierno o cese en la colaboración de las mutuas de accidentes de trabajo y enfermedades profesionales siempre que las circunstancias del caso lo aconsejasen (art. 44 LISOS); la suspensión temporal y la retirada definitiva de la autorización para colaborar a aquellos empresarios que cooperen voluntariamente en la gestión, también siempre que "las circunstancias del caso lo requieran, en beneficio de la corrección de las deficiencias observadas" (art. 45 LISOS). Cabe, asimismo, la imposición de un recargo entre el 30 y el 50 por 100 de todas las prestaciones de Seguridad Social debidas a la víctima o sus familiares cuando el accidente de trabajo o la enfermedad profesional derive de una falta de medidas de seguridad (art. 123 Real Decreto Legislativo 1/1994, de 20 de junio, por el que se aprueba el texto refundido de la Ley General de Seguridad Social) ${ }^{107}$.

Además, las empresas de trabajo temporal pueden perder la autorización para operar en el sector si incumplen la obligación de "mantener una estructura organizativa que responsa a las características que se valoraron" para su concesión (art. 2.5 Ley 14/1994). Esta misma consecuencia de extinción de autorización puede derivarse para las agencias privadas de colocación del incumplimiento de sus obligaciones legales o concertadas [art. 17.1 c) y e) Real Decreto 735/1995, de 5 de mayo]. También puede ser cancelada, por la comisión de faltas graves y muy graves, "la acreditación otorgada por la autoridad laboral" a "determinadas entidades especializadas" en materia de seguridad y salud en el trabajo, como "servicios de prevención", y en actividades de "auditoría" o "formación" [art. 40.2 c) in fine LISOS]. Por lo que se refiere a las Cooperativas, procede la descalificación de la sociedad por la comisión de infracciones muy graves (arts. 40.4 y 48.3 LISOS). En fin, el art. 49.1 c) Ley 30/2007, de 30 de octubre, de Contratos del Sector Público, establece la prohibición de contratar con la Administración para aquellas empresas que hayan sido "sancionadas con carácter firme por infracción grave en materia de disciplina de mercado, en materia profesional o en materia de integración laboral y de igualdad de oportunidades y no discriminación de las personas con discapacidad o por infracción muy grave en materia social, incluidas las infracciones en materia de prevención de riesgos laborales"108.

\section{Atenuantes y agravantes}

En tanto en cuanto -sin perjuicio de otras accesorias-, la sanción pecuniaria constituye la principal medida sancionadora consagrada por el ordenamiento, procede poner de manifiesto que, en aras a su determinación es necesario considerar los criterios y circunstancias atenuantes o agravantes de la infracción, para, una vez pon-

107 Iglesias Cabero, M.: “El recargo de prestaciones económicas de la Seguridad Social por falta de medidas de seguridad, en caso de accidente de trabajo y enfermedad profesional”, Revista del Ministerio de Trabajo y Asuntos Sociales, núm. 78, 2008, pp. 201 y ss.

108 Rodríguez Escanciano, S.: Subcontratación de concesiones administrativas. Problemas laborales, Madrid (Marcial Pons), 2006, pp. 33 y ss. 
derada la situación fáctica, poder incardinarla en la graduación prevista dentro del marco legal aplicable ${ }^{109}$. Así, y entre los criterios generales de graduación, cabe mencionar -recordando conceptos a los que ya se hizo referencia- los siguientes fundamentales (art. 39.2 LISOS) ${ }^{110}$ :

1. La negligencia o intencionalidad del sujeto infractor.

2. El fraude o connivencia en la comisión de la infracción.

3. El incumplimiento de advertencias previas y requerimientos de la Inspección de Trabajo.

4. La cifra de negocios de la empresa.

5. El número de trabajadores o de beneficiarios afectados.

6. El perjuicio causado.

7. La cantidad defraudada.

8. La reincidencia, entendida como reiteración de una infracción del mismo tipo y calificación que la que motivó una sanción anterior, en el plazo de los 365 días siguientes a la notificación de ésta. Tal circunstancia puede incrementar la sanción hasta el duplo del grado de la sanción correspondiente a la infracción cometida, sin exceder, en ningún caso, de las cuantías máximas previstas para cada clase de infracción (art. 41 LISOS).

Con carácter más específico, en materia de prevención de riesgos laborales, se tendrán en cuenta los siguientes criterios (art. 39.3 LISOS): a) La peligrosidad de las actividades desarrolladas en la empresa o centro de trabajo; b) El carácter permanente o transitorio de los riesgos inherentes a dichas actividades; c) La gravedad de los daños producidos o que hubieran podido producirse por la ausencia o deficiencia de las medidas preventivas necesarias; d) El número de trabajadores afectados; e) Las medidas de protección individual o colectiva adoptadas por el empresario y las instrucciones impartidas por éste en orden a la prevención de riesgos; f) El incumplimiento de las advertencias o requerimientos previos a que se refiere el art. 43 LPRL; g) La inobservancia de las propuestas realizadas por los servicios de prevención, los delegados de prevención o el comité de seguridad y salud de la empresa para la corrección de las deficiencias legales existentes; h) La conducta general seguida por el empresario en orden a la estricta observancia de las normas en materia de prevención de riesgos laborales ${ }^{111}$. 2655).

109 SSTS, Cont-Admtivo, 15 marzo 1988 (RJ 2293), 30 octubre 1990 (RJ 7558) y 28 febrero 2000 (RJ

110 Sánchez-Terán Hernández, J.M.: Los criterios de graduación de las sanciones administrativas en el orden social, cit., pp. 91 y ss.

111 Martín Jiménez, R.: Los actos administrativos laborales y su control jurisdiccional, Madrid (CES), 2001, pp. 326 y ss. 
Igualmente, en materia de sociedades cooperativas, las sanciones se graduarán, a efectos de su correspondiente imposición, atendiendo al número de socios afectados, repercusión social, malicia o falsedad y capacidad económica de la cooperativa (art. 39.4 LISOS).

En fin, y como no podía ser de otra manera, los criterios de graduación, cuando vengan contemplados expresamente en las infracciones correspondientes como descriptivas de la conducta infractora o formando parte del propio ilícito administrativo, imposibilitan que se puedan tener en cuenta nuevamente a la hora de agravar la sanción, en tanto que entender lo contrario supondría incurrir ante una duplicidad en su consideración (art. 39.5 LISOS). Todo ello sin olvidar que, de acuerdo con el art. 7.3 Real Decreto 928/1998, las sanciones impuestas prescribirán a los cinco años, a contar desde el día siguiente a aquel en que adquiera firmeza la resolución por la que se impone la sanción.

\section{PROCEDIMIENTO SANCIONADOR}

Partiendo del dato cierto de que a la Administración laboral, por medio de la Inspección de Trabajo, se encomienda el control coactivo del cumplimiento de las normas por parte de los sujetos obligados a ello, no cabe perder de vista que el acto sancionatorio de la Administración debe ir precedido ad solemnitatem por un procedimiento ad hoc. Se trata de un iter, en el cual la Ley ha prefijado el modus operandi de los órganos administrativos que han de actuar ante la posible comisión de una infracción administrativa del orden social, con los consiguientes efectos anulatorios que su inobservancia llevaría aparejados sobre la eventual imposición de una sanción, aunque la Administración llevara razón sobre el fondo de la cuestión (su procedencia).

La disposición adicional $4 .{ }^{\text {a }}$ LIT anuncia la regulación, por norma reglamentaria, del procedimiento administrativo especial para la imposición de sanciones y de liquidaciones en el orden social, mandato que se ha cumplido por el Real Decreto 928/1998, diferente al general previsto por Real Decreto 1398/1993, de 4 de agosto, que únicamente tiene carácter supletorio (art. 1.3).

Bajo la premisa fundamental de garantizar la participación como parte activa del inculpado, en ejercicio de un elemental derecho de defensa ${ }^{112}$, el procedimiento se inicia -como no podía ser de otra forma- por la Inspección de Trabajo, que se encarga de su instrucción, y termina con la resolución, competencia de la Autoridad Laboral correspondiente. Esta separación funcional pretende operar como una garantía de imparcialidad de la autoridad decisoria derivada de la vigencia del principio acusatorio ${ }^{113}$.

112 STCO 23/2007, de 12 de febrero.

113 Moreu Carbonell, E.: "Las especialidades del procedimiento sancionador en el orden social y para la liquidación de cuotas de la Seguridad Social ¿Excesos en la potestad inspectora?”, Actualidad Labo226 ral, núm. 19, 1999, p. 376. También, SSTCO 54/2003, de 24 de marzo; 228/2002, de 8 de diciembre ó 71/2005, 


\section{Comprobación del cumplimiento de las normas sociales}

Además de sus funciones de asesoramiento, de información y dictamen en muy diversas materias (expedientes de regulación de empleo, clasificación profesional, accidentes de trabajo...), la Inspección de Trabajo tiene una forma característica de ejercitar su función de hacer cumplir la legislación laboral, consistente en la incoación e instrucción de procedimientos administrativos de sanción y de exacción de cuotas de Seguridad Social ${ }^{114}$.

Se entiende por instrucción el conjunto de actos necesarios para la determinación, conocimiento y comprobación de los datos en virtud de los cuales deba pronunciarse la resolución, que tiene por finalidad proporcionar al órgano competente los elementos de juicio necesarios para una adecuada decisión ${ }^{115}$.

Desde tal perspectiva -y tras la aprobación de la Ley 25/2009, de 22 de diciembre, de modificación de diversas leyes para su adaptación a la Ley sobre el libre acceso a las actividades de servicio y su ejercicio-, la actividad inspectora podrá comenzar mediante alguna de las formas previstas en el art. 13 LIT $^{116}$ :

1. Por orden superior de la autoridad competente, tanto de la Administración General del Estado como de la Autonómica, a través de la Jefatura de la Inspección Provincial o, en su caso, de sus unidades especializadas, que emitirán por escrito la correspondiente orden de servicio con el "señalamiento de actuaciones concretas a los Inspectores y a los equipos de inspección” [art. 9.1 a) RD 928/1998].

2. Por orden de servicio de las Jefaturas de la Inspección Provincial, de sus Unidades especializadas o del Inspector encargado del equipo, "en aplicación de los planes, programas y directrices sobre actuación de la Inspección” [art. 9.1b) RD 928/1998].

3. Por petición de cualquier órgano jurisdiccional, "cuando determine su objeto, amplitud y finalidad" [art. 9.1 c) RD 928/1998]. Por su parte, los Juzgados y Tribunales habrán de facilitar a la Inspección, de oficio o a petición de la misma, "los datos de trascendencia para la función inspectora que se desprendan de las actuaciones en que conozcan y que no resulten afectados por el secreto sumarial” (art. 9.5 LIT).

4. Por petición concreta de los organismos de la Seguridad Social (que podrán "recabar la actuación inspectora y encomendar a la Inspección las comprobaciones que resulten necesarias para su gestión cuando correspondan al ámbito de la acción inspectora") o a solicitud de otra Administración Pública [arts. 9.1 d) y 10.1 RD 928/1998].

114 Benita Fernández, F.: Infracciones y sanciones en el orden social: guía de normas de actuación y procedimiento de la Inspección, Valladolid (Lex Nova), 1997, pp. 53 y ss.

115 AA.VV (Sempere Navarro, A.V., Coord.): Derecho Sancionador Público del trabajo, cit., p. 678.

116 Mercader Uguina, J.R. y Tolosa Tribiño, C.: Derecho Administrativo Laboral, cit., pp. 602 y ss. 
5. Por propia iniciativa del Inspector de Trabajo, cuya actuación se sujetará a "criterios de eficacia y de oportunidad", acomodándose a la "programación vigente en la Inspección de su destino" [art. 9 e) RD 928/1998].

6. Por denuncia de hechos presuntamente constitutivos de infracción en el orden social [art. 9.1 f) RD 928/1998]. Debe tenerse en cuenta, en este marco, que la acción de denuncia del incumplimiento de la legislación del orden social es "pública" (el escrito deberá contener, además de los datos de identificación personal del denunciante y su firma, los hechos, la fecha y el lugar de su acaecimiento, la concreción de los presuntos responsables y demás circunstancias relevantes), aunque el acusador "no pueda alegar la consideración de interesado" a ningún efecto en la fase de investigación, aun cuando sí pueda tenerla si se incoa el correspondiente procedimiento sancionador (art. 13.2 LIT). En cualquier caso, no se tramitarán aquellas denuncias que: a) sean anónimas; b) se refieran a materias cuya vigilancia no corresponda a la Inspección de Trabajo; c) manifiestamente carezcan de fundamento o resulten ininteligibles; o d) coincidan con asuntos de los que esté conociendo un órgano jurisdiccional (art. 13.2 LIT). En fin, la Inspección podrá solicitar al denunciante su comparecencia para "ratificar, ampliar o concretar el contenido de la denuncia" (art. 24.2 RD 138/2000).

Sea como fuere, la Inspección de Trabajo puede realizar su actividad (y abrir, en su caso, un "período de información previa" con el fin de conocer las circunstancias del caso concreto y la conveniencia o no de iniciar la actividad inspectora), a través de una triple modalidad de actuación (art. 14 LIT) ${ }^{117}$ :

A) Mediante visita (por uno o varios funcionarios y durante el tiempo necesario) a los centros o lugares de trabajo, sin necesidad de aviso previo. Cuando, iniciada la visita de inspección, no fuese posible su finalización por no aportar el sujeto sometido a fiscalización los "antecedentes o documentación solicitados", la actuación inspectora proseguirá en virtud de "requerimiento" para su aportación al funcionario actuante.

B) Mediante comparecencia de los sujetos obligados ante el funcionario actuante en la oficina pública que éste determine en virtud de requerimiento, "aportando la documentación que se señale en cada caso o para efectuar las aclaraciones pertinentes".

C) En virtud de expediente administrativo, cuando el contenido del mismo permita iniciar y finalizar la actuación inspectora. Sin ánimo exhaustivo, cabe hacer referencia a los siguientes tipos de expedientes: 1) Registrales (resultados electorales, convenios colectivos, contratos, empresas de trabajo temporal y agencias privadas de colocación, cooperativas y sociedades laborales, entidades colaboradoras en la

117 Por extenso, García Rubio, M.A.: La Inspección de Trabajo y Seguridad Social (doctrina y jurisprudencia), Valencia (Tirant Lo Blanch), 1999, pp. 288 y ss. 
gestión de la Seguridad Social o servicios de prevención). 2) Prestacionales (Seguridad Social o Fondo de Garantía Salarial). 3) Autorizatorios (expedientes de regulación de empleo, permisos de trabajo, mutuas patronales, empresas colaboradoras en la gestión de la Seguridad Social, acreditación de los servicios de prevención o auditorías técnicas, agencias privadas de colocación y empresas de trabajo temporal).4) Interdictales (paralización de trabajos, suspensión de actividades o cierre del centro de trabajo). 5) Cuasijurisdiccionales (resolución de conflictos por la autoridad laboral en materia de locales y tablones de anuncios) ${ }^{118}$.

D) Mediante comprobación de datos o antecedentes que obren en las Administraciones Públicas o éstas le suministren si fueren de la Unión Europea.

En el ejercicio de sus funciones, los Inspectores de Trabajo y Seguridad Social tienen el carácter de autoridad pública y poseen las siguientes facultades ${ }^{119}$ :

1. Entrar libremente, en cualquier momento y sin previo aviso, en todo centro de trabajo, establecimiento o lugar sujeto a inspección, y permanecer en el mismo, salvo que coincidiese con el domicilio de la persona física afectada, en cuyo caso deberá "obtener su expreso consentimiento o, en su defecto, la oportuna autorización judicial” (art. 5.1 LIT), a fin de garantizar la inviolabilidad de aquél (art. 18.2 CE). Al efectuar una visita de inspección, deberán "comunicar su presencia" al empresario o a su representante, "a menos que consideren que dicha comunicación pueda perjudicar el éxito de sus funciones" (art. 5.1 LIT). Si la visita tiene por objeto la comprobación del cumplimiento de las normas sobre prevención de riesgos laborales, el Inspector comunicará su presencia, además de al empresario o a su representante o a la persona inspeccionada, al comité de seguridad y salud, al delegado de prevención o, en su ausencia, a los representantes legales de los trabajadores, "a fin de que puedan acompañarle durante el desarrollo de su visita y formularle las observaciones que estimen oportunas", a menos que el funcionario considere que ello puede perjudicar el éxito de sus actuaciones (art. 40.2 LPRL). En todo caso, la Inspección deberá informar a los delegados de prevención sobre los resultados de tales visitas respecto de las medidas adoptadas como consecuencia de las mismas (art. 40.3 LPRL).

2. Hacerse acompañar en las visitas de inspección por los trabajadores, sus representantes y por los peritos y técnicos de la empresa o habilitados oficialmente, que estime necesario para el mejor desarrollo de la función inspectora (art. 5.2 LIT).

3. Practicar cualquier diligencia de investigación, examen o prueba que considere precisa "para comprobar que las disposiciones legales se observan correctamente" y, en particular, para: a) requerir información, sólo o ante testigos, al empresario o al personal de la empresa "sobre cualquier asunto relativo a la apli-

118 AA.VV (Sempere Navarro, A.V., Coord.): Derecho Sancionador Público del Trabajo, cit., p. 347.

119 González Biedma, E.: La Inspección de Trabajo y el control de la aplicación de la norma laboral, Pamplona (Aranzadi), 1999, pp. 146 y ss. 
cación de las disposiciones legales", así como a la "identificación, o razón de su presencia, de las personas que se encuentren en el centro de trabajo inspeccionado"; b) exigir la comparecencia (en el centro inspeccionado o en las oficinas públicas designadas por el Inspector actuante) del empresario o de sus representantes y encargados, de los trabajadores, de los perceptores o solicitantes de prestaciones sociales y de cualesquiera sujetos incluidos en su ámbito de actuación; c) examinar en el centro de trabajo (o requerir su presentación en las oficinas públicas correspondientes) la documentación y los libros de la empresa con trascendencia en la verificación del cumplimiento de la legislación del orden social; d) tomar o sacar muestras de sustancias y materiales utilizados o manipulados en el establecimiento, realizar mediciones, obtener fotografías, vídeos, grabación de imágenes, levantar croquis y planos ("siempre que se notifique al empresario o su representante"); y e) obtener copias y extractos de los documentos mencionados en el párrafo anterior (art. 5.3 LIT).

4. Adoptar, en cualquier momento del desarrollo de sus actuaciones, las medidas cautelares que se estimen oportunas y que sean proporcionadas al fin que se persiga, "para impedir la destrucción, desaparición o alteración" de la documentación mencionada en el número precedente, "siempre que no cause perjuicio de difícil o imposible reparación a los sujetos responsables o implique violación de derechos" (art. 5.4 LIT).

5. Llevar a la práctica, en su caso, cualesquiera de las siguientes medidas (art. 7 LIT): a) Advertencia y requerimiento al sujeto responsable, "cuando las circunstancias del caso así lo aconsejen y siempre que no se deriven perjuicios directos a los

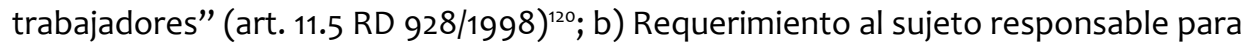
que, en el plazo que se señale, "adopte las medidas en aras al cumplimiento de la normativa del orden social”, incluso con su justificación ante el funcionario actuante (art. 11.5 RD 928/1998); c) Requerimiento al empresario a fin de que, en un plazo determinado, lleve a efecto "las modificaciones que sean precisas en las instalaciones, en el montaje o en los métodos de trabajo que garanticen el cumplimiento de las disposiciones relativas a la salud o la seguridad de los trabajadores (art. 11.5 RD 928/1998) ${ }^{121}$; d) Iniciación de un procedimiento sancionador y de un expediente liquidatorio por débitos a la Seguridad Social y conceptos de recaudación conjunta; e) Incoación de procedimientos de oficio para la inscripción de empresas, afiliación y altas y bajas de trabajadores en el régimen correspondiente de la Seguridad Social; $f$ ) Incoación de procedimientos para el encuadramiento de empresas y trabajadores en el régimen de la Seguridad Social que proceda, sin perjuicio del inicio del correspondiente expediente liquidatorio; g) Instancia del correspondiente organismo de la sus-

120 Fernández Orrico, F.J.: “Las actuaciones de advertencia y los requerimientos de la Inspección de Trabajo y Seguridad Social”, Revista del Ministerio de Trabajo y Asuntos Sociales, núm. 78, 2008, pp. 139 y ss.

230121 Gámez Orea, M.: “Actas de ad 
pensión o cese en la percepción de prestaciones sociales, "si se constatase su obtención o disfrute en algún incumplimiento de la normativa que las regula" (arts. 37 y 38 RD 928/1998); h) Instancia del órgano administrativo competente de la declaración del recargo de las prestaciones económicas en caso de accidente de trabajo o enfermedad profesional causados por falta de medidas de seguridad e higiene (art. 27 RD 928/1998); i) Propuesta de recargos o reducciones en las primas de aseguramiento de accidentes de trabajo y enfermedades profesionales, "en relación a empresas por su comportamiento en la prevención de riesgos y salud laborales, con sujeción a la normativa aplicable"; j) Orden de paralización inmediata de trabajo o tareas por inobservancia de la normativa sobre prevención de riesgos laborales, de concurrir riesgo grave e inminente para la seguridad o salud de los trabajadores (art. 11.3 y 4 RD 928/1998): k) Comunicación al organismo competente de los incumplimientos comprobados en la aplicación y destino de ayudas y subvenciones para el fomento del empleo, formación profesional ocupacional y promoción social; l) Propuesta a su respectivo Jefe de la formulación de demandas de oficio ante la jurisdicción de lo social en la forma prevista en la LPL (arts. 6 y 19 RD 928/1998); m) En fin, y en cláusula abierta, cuantas otras medidas se deriven de la legislación en vigor ${ }^{122}$.

En todo caso, el resultado de las actuaciones practicadas deberá quedar siempre expresado en el libro de visitas que las empresas están obligadas a tener en cada centro de trabajo ${ }^{123}$.

\section{Las actas de infracción}

Realizadas las comprobaciones oportunas, si se han detectado incumplimientos, el procedimiento sancionador se inicia formalmente con el levantamiento de un acta de infracción (a modo de pliego de cargos), en la cual, para garantizar la legalidad de la actuación administrativa y evitar la indefensión del sujeto imputado, deberá constar el siguiente contenido (art. 53.1 LISOS) ${ }^{124}$ :

1. La identificación del sujeto infractor (nombre y apellidos o razón social, domicilio y actividad productiva), así como, en su caso, de los posibles responsables solidarios y subsidiarios, con indicación para ambos supuestos de tal circunstancia, de la fundamentación jurídica de dicha responsabilidad y de los mismos datos exigidos para el sujeto responsable principal [art. 53.1 d) LISOS].

122 De Val Arnal, J.J.: “Actuaciones de advertencia y recomendación”, en AA.VV (García Blaso, J. y Monereo Pérez, J.L., Dirs.): Comentario sistemático al texto refundido de la Ley de Infracciones y Sanciones en el orden social, Granada (Comares), 2005, p. 666.

123 Gutiérrez Alonso, J.J.: "Procedimiento sancionador y sistema de recursos administrativos en el Texto Refundido de la Ley de Infracciones y Sanciones en el Orden Social”, en AA.VV (Cavas Martínez, F. y Luján Alcaraz, J., Dirs.): Infracciones y Sanciones en el Orden Social. Régimen Jurídico, cit., p. 435.

124 García Rubio, M.A.: La Inspección de Trabajo y Seguridad Social (doctrina y jurisprudencia), cit., pp. 416 y ss. 
2. La expresión de los hechos constatados por el funcionario actuante que hayan motivado el acta, haciendo destacar "los relevantes a efectos de la determinación y tipificación de la infracción y de la graduación de la sanción”, así como si la actuación inspectora ha sido realizada mediante visita, comparecencia o por expediente administrativo [art. 14.1 b) RD 928/1998]. Cuando el acta de infracción se practique como consecuencia de "informe" emitido por los funcionarios técnicos que ejerzan labores de colaboración pericial y asesoramiento de la Inspección en materia de prevención de riesgos laborales, se hará en la misma mención expresa de tal circunstancia, con la indicación de que se actúa por expediente administrativo, incorporándose a su texto además "el relato de hechos y los demás datos relevantes del informe" (art. 53.5 LIT). La Inspección recabará de estos funcionarios "la subsanación de sus informes", cuando considere que el detalle técnico referido es insuficiente a efectos sancionadores, procediendo a su archivo en caso de no hacerse en término de quince días y sin perjuicio de nuevas comprobaciones (art. 53.5 LISOS).

3. La determinación de la infracción que se impute, "con expresión del precepto vulnerado" [art. 53.1 b) LISOS]. En caso de que en la misma actuación inspectora se estimasen "varias presuntas infracciones", deberá efectuarse la acumulación en un solo acta de las correspondientes a una misma materia (respetándose en todo caso la distribución de competencias entre la Administración General del Estado y la de la Comunidad Autónoma respectiva), salvo en los supuestos de tramitación simultánea de actas de infracción y liquidación por los mismos hechos, de responsabilidad solidaria o subsidiaria, y de infracciones relacionadas causalmente con un accidente de trabajo o enfermedad profesional (art. 16 RD 928/1998).

4. La calificación de la infracción [art. 53.1 c) LISOS].

5. La propuesta de sanción, su graduación (en su caso) y cuantificación [art. 53.1 c) LISOS], debiendo incluirse expresamente además la propuesta de las "sanciones accesorias" que procedan como vinculadas a la sanción principal [art. 14.1 e) RD 928/1998).

6. La determinación del órgano competente para resolver y el plazo para la interposición de alegaciones ante el mismo [art. 14.1 f) RD928/1998]

7. La indicación del funcionario que levanta el acta de infracción y firma del mismo [art. 14.1 g) RD 928/1998].

8. La fecha del acta de infracción [art. 14.1 h) RD 928/1998].

9. La determinación de las medidas provisionales que fuesen necesarias para "asegurar la eficacia de la resolución y evitar el mantenimiento de los efectos de la 232 infracción” (art. 14.2 RD 928/1998). 
En fin, como modalidades singulares de actas de infracción, cabe mencionar las siguientes ${ }^{125}$ : a) Con estimación de perjuicios económicos, cuando el Inspector considere que de la presunta conculcación de la legislación laboral se derivan detrimentos de esta naturaleza para los trabajadores afectados, dando inicio al procedimiento sancionador, común a toda infracción, y también a un procedimiento de oficio ante la jurisdicción del orden social (art. 14.3 RD 928/1998). b) Por obstrucción, cuando la obstaculización que pueda proceder de los obligados a soportar la actuación de la Inspección de Trabajo pueda generar responsabilidad administrativa (art. 50.2 LISOS) ${ }^{126}$. c) De liquidación, cuando las deudas por cuotas a la Seguridad Social sean originadas por falta de afiliación o de alta de trabajadores en cualquiera de los regímenes del sistema de la Seguridad Social, diferencias de cotización por trabajadores dados de alta, derivación de la responsabilidad del sujeto obligado al pago o por aplicación indebida de las bonificaciones en las cotizaciones, prevista reglamentariamente para la financiación de las acciones formativas del subsistema de formación profesional continua ${ }^{127}$.

\section{Alegaciones}

Teniendo en cuenta que los hechos reflejados en el acta gozan de presunción legal de certeza ${ }^{128}$, siempre que ésta se haya levantado de acuerdo con las exigencias legales (art. 53.2 LIT) ${ }^{129}$, deviene necesario notificar dicho documento al sujeto responsable en un plazo de diez días contados a partir del término de la actuación inspectora (art. 17 RIS) ${ }^{130}$. Conviene aclarar, no obstante, que se trata de una presunción de veracidad de carácter iuris tantum, sobre los hechos, que admite la lógica prueba

125 Carratalá Teruel, J.L.: “En torno al nuevo procedimiento sancionador por infracciones en el orden social”, Tribuna Social, núm. 66, 1996, pp. 79 y ss.

126 La obstrucción puede ser leve (mero transcurso del cumplimiento de obligaciones de información, comunicación o comparecencia), grave y muy grave (esta última en las acciones u omisiones que tengan por objeto impedir la entrada o permanencia del funcionario en el centro de trabajo; negativa a identificarse o a identificar o dar razón de personas que se encuentren en dicho centro, realizando cualquier actividad; coacción, amenaza o violencia ejercida sobre el funcionario o reiteración de conductas de obstrucción calificadas como graves (arts. 50.2, 3 y 4 LISOS). Calvente Menéndez, J.: “Organización, funciones y medios de la Inspección”, en AA.VV (Vázquez González, I., Coord.): La Inspección de Trabajo y Seguridad Social, Pamplona (Aranzadi), 1999, pp. 43 y ss. En la doctrina judicial, STS, Cont-Admtivo, 19 enero 2004 (RJ 420).

127 Sánchez Grande, A. y Mercader Uguina, J.R.: “El nuevo procedimiento para la imposición de sanciones por infracciones en el orden social y para la extensión de actas de liquidación de cuotas de la Seguridad Social”, Relaciones Laborales, T. II, 1996, pp. 898 y ss. ó Vázquez González, I.: “El procedimiento para la liquidación de cuotas a la Seguridad Social”, en AA.VV (Vázquez González, I., Coord.): La Inspección de Trabajo y Seguridad Social, Pamplona (Aranzadi), 1999, pp. 383 y ss.

128 SSTS, Cont-Admtivo, 18 enero y 18 marzo 1991 (Ar. 1508 y 5330), 26 junio 1996 (Ar. 5330) y 20 junio 2007 (RJ 641).

129 García Rubio, M.A.: La presunción de certeza de las actas de la Inspección de Trabajo y Seguridad Social, Valencia (Tirant Lo Blanch), 1999.

130 La formalización de la acusación del sujeto imputado se lleva a cabo mediante la notificación del acta, pues de dicha notificación del acto administrativo depende su eficacia. SSTCo 291/2000, de 30 de noviembre ó 226/2007, de 22 de octubre. 
en contrario y que es eficaz sólo frente al administrado y en sede administrativa, no ante un órgano judicial. No implica, por tanto, presunción de culpabilidad ${ }^{131}$.

Cuando el acta de infracción afecta a solicitantes y beneficiarios de prestaciones, ha de comunicarse a las correspondientes entidades gestoras, a efectos de la posible suspensión cautelar de las mismas. En el supuesto de las actas de infracción y de liquidación por unos mismos hechos, las notificaciones se practican al presunto sujeto o sujetos responsables simultáneamente, y el plazo para la impugnación de ambas será conjunto ${ }^{132}$.

El procedimiento continúa con la presentación de alegaciones por parte del interesado, en el plazo de quince días, con derecho a vista de los documentos obrantes en el expediente, sin más restricciones que las necesarias para asegurrar la confidencialidad del origen de cualquier queja (art. 12.2 LIT). Al tiempo, el órgano instructor llevará a cabo todas las actuaciones que exija la tramitación del expediente, recabando informe de los Inspectores de Trabajo actuantes y dando audiencia al interesado si se desprende la existencia de hechos distintos de los incorporados en el acta [arts. 52.1 b) LIT y 18 Real Decreto 928/1998]. Todo ello sin perder de vista que las alegaciones constituyen el elemento propio que tienen los sujetos imputados en una infracción para aportar datos fácticos o jurídicos al expediente capaces de servir de fundamento de la exoneración en la resolución ${ }^{133}$.

Aunque el Real Decreto 928/1998 no contiene previsión alguna respecto al cauce de desarrollo de pruebas, debe considerarse su plena posibilidad. Por un lado, por cuanto el art. 17.4 in fine de dicha norma reglamentaria alude al escrito de alegaciones "y los medios de prueba de que intente valerse el sujeto o sujetos responsables" que, como un todo, debe presentarse ante el órgano competente para resolver el expediente. Por otro, no cabe olvidar que la doctrina del Tribunal Constitucional es sumamente clara cuando reconoce al sujeto pasivo de un procedimiento administrativo sancionador el derecho a proponer, y a que sean admitidos y practicados, los medios de prueba pertinentes para su defensa. En fin, no procede silenciar tampoco el carácter supletorio de la LRJAP, cuyo art. 137, especialmente se refiere a la práctica, de oficio o a la admisión de las propuestas por el presunto responsable, de cuantas pruebas sean adecuadas para la determinación de hechos y posibles responsables, de tal forma que sólo pueden declararse improcedentes aquellas pruebas que por su relación con los hechos no puedan alterar la resolución final a favor del presunto imputado ${ }^{134}$. Por lo que se refiere a los medios probatorios que se puedan practicar, el art. 80 LRJAP alude a "cualquiera admisible en derecho", dando de esta forma cabida a un gran elenco de posibilidades, claro está siempre que resulten necesarias para acreditar las propias alegaciones vertidas. La

131 García Rubio, M.A.: La Inspección de Trabajo y Seguridad Social (doctrina y jurisprudencia), cit., pp. 505 y ss.

132 AA.VV (Sempere Navarro, A.V., Coord.): Derecho Sancionador Público del Trabajo, cit., p. 371.

133 AA.VV (Sempere Navarro, A.V., Coord.): Derecho Sancionador Público del Trabajo, cit., p. 371.

134 Duréndez Sáez, I.: “Tramitación del procedimiento sancionador del orden social: acusación e

234 instrucción”, Revista del Ministerio de Trabajo y Asuntos Sociales, núm. 78, 2008, pp. 132 y ss. 
apertura del período probatorio supondrá, en su caso, que se tengan que practicar por un plazo no superior a treinta días ni inferior a diez ${ }^{135}$.

En todo caso, si de las alegaciones y pruebas presentadas se deduce la competencia de los órganos judiciales (típicamente, si se niega la laboralidad de la relación profesional), se suspenderá el procedimiento administrativo para que la autoridad laboral inste el procedimiento de oficio ante los Juzgados de lo Social mediante escrito-demanda. Una vez recaiga sentencia firme, continuará el expediente si el pronunciamiento jurisdiccional, por su fallo, lo permite, o se archivará en caso contrario ${ }^{136}$.

En fin, sobre la propuesta de resolución no se establece una regulación específica en el Real Decreto 928/1998, pero atendiendo a la norma que pauta con carácter general el procedimiento para el ejercicio de la potestad sancionadora, cual es el Real Decreto 1398/1993, que se asume como supletorio, ha de entenderse que ha de ser motivada y debe fijar los hechos, especificándose los que se consideren probados y su exacta calificación jurídica, además de determinar la infracción que, en su caso, constituyan y la persona o personas que resultan responsables, concretando la sanción que propone para su imposición y las medidas provisionales que se hubieran adoptado. A sensu contrario, también podrá proponer la declaración de no existencia de infracción o responsabilidad y, por tanto, el archivo de las actuaciones ${ }^{137}$.

\section{Resolución}

El procedimiento administrativo sancionador se ultima con una fase decisoria en la que definitivamente se plasma el ius puniendi o, en su caso, la declaración que no encontrase acreditada la comisión del ilícito administrativo imputado.

La resolución del expediente corresponde a la autoridad administrativa competente del Ministerio de Trabajo o de la Comunidad Autónoma [art. 52.1 d) LISOS y art. 20 Real Decreto 928/1998 $]^{138}$. Ahora bien, antes de dictar el pronunciamiento corres-

135 AA.VV (Sempere Navarro, A.V., Coord.): Derecho Sancionador Público del Trabajo, cit., p. 372.

136 Gámez Orea, M.: “El procedimiento sancionador”, en AA.VV (Vázquez González, I., Coord.): La Inspección de Trabajo y Seguridad Social, Pamplona (Aranzadi), 1999, pp. 339 y ss.

137 AA.VV (Sempere Navarro, A.V., Coord.): Derecho Sancionador Público del Trabajo, cit., p. 373.

138 Según el art. 48 LISOS, redactado conforme a la disposición final 1. ${ }^{a}$ Ley 38/2007, de 16 de noviembre, la prerrogativa para imponer las sanciones corresponde: a la autoridad competente a nivel provincial hasta 12.500 euros; al Director General competente, hasta 62.500 euros; al Ministro de Trabajo, hasta 125.000 euros; y al Consejo de Ministros, hasta 187.515 euros. En materia de prevención de riesgos laborales, respectivamente a las mismas autoridades hasta 40.985, 123.000, 409.900 y 819.780 euros. En caso de acumulación de infracciones sobre la misma materia en un solo procedimiento, será competente para imponer la sanción por la totalidad de aquéllas el órgano que lo sea para imponer la de mayor cuantía. Si la Comunidad Autónoma ha asumido, entre las competencias de ejecución de la legislación laboral, la relativa a la imposición de sanciones administrativas, la potestad punitiva "se ejercerá por los órganos y con los límites de distribución que determine cada Comunidad Autónoma” (art. 48.5 LIS). AA.VV.: Inspección de Trabajo 2007-2008, Madrid (Francis Lefebvre), 2006, pp. 316 y ss. 
pondiente, el órgano competente puede propiciar la necesidad de nuevas diligencias, con el fin de complementar la documentación de que se dispone para poder pronunciarse con la certeza y garantía necesaria ${ }^{139}$. Sobre estas diligencias no existe límite, pudiendo ir dirigidas a recabar mayores datos o noticias adicionales del instructor, presunto responsable o terceros ${ }^{140}$. Bien parece que, aunque nada diga el RD 928/1998, si como consecuencia de estas nuevas diligencias se incorporaran extremos que pudieran incidir en los hechos, habría que posibilitar un ulterior trámite de audiencia al responsable para que sea conocedor de los mismos y brindarle la oportunidad de realizar alegaciones, como resorte que impida su indefensión ${ }^{141}$.

En todo caso, si se hubieran formulado alegaciones, el órgano competente, antes de resolver el expediente, dará nueva audiencia al interesado por término de ocho días hábiles, permitiéndole acceder a lo actuado, siempre que de las diligencias practicadas se desprenda la existencia de hechos distintos a los reseñados en el acta, pudiendo formular nuevas aportaciones en su defensa por término de otros tres días, a cuyo fin el expediente quedará visto para la resolución (art. 18.4 RD 928/1998) ${ }^{142}$. Claramente puede deducirse que se trata de un trámite dirigido en estricto beneficio de los presuntos responsables ${ }^{143}$, cuya finalidad esencial es que éstos conozcan el conjunto de datos que figuran en el expediente y que van a servir para configurar la resolución definitiva, obviamente por la circunstancia de aparecer hechos distintos a los que en principio figuraban en el acta ${ }^{144}$.

La resolución, que pone fin al procedimiento sancionador, ha de ser expresa y motivada y deberá ser dictada por el órgano competente en el plazo de diez días desde la recepción de la propuesta de resolución o, en su caso, desde la realización de la última diligencia. Puede confirmar o modificar la propuesta de sanción del órgano instructor o decidir no imponer sanción alguna por no haberse acreditado la infracción o no existir motivo válido que la fundamente. Si se entiende que el acta carece de requisitos imprescindibles o que da lugar a indefensión de los interesados se acordará directamente su anulación (art. 20 RD 928/1998).

Como acto motivado que es, dicho acto administrativo ha de permitir que se conozcan las razones de hecho y de derecho que justifican la decisión, como garantía de la objetividad que debe presidir la actuación de la Administración, y a fin de posibilitar la impugnación de la correspondiente sanción ante los órganos apropiados para ello ${ }^{145}$. Además, la exigencia de congruencia implica que el pronunciamiento del órgano sancionador deje resueltos todos los extremos debatidos, aunque la solución pro-

139 Minondo Sanz, J.: Fundamentos de la Inspección de Trabajo y Seguridad Social, Madrid (Ministerio de Trabajo), 2000, pp. 357 y ss.

140 Gámez Orea, M.: “El procedimiento sancionador”, cit., pp. 341 y ss.

141 AA.VV (Sempere Navarro, A.V., Coord.): Derecho Sancionador Público del Trabajo, cit., p. 374.

142 AA.VV (Sempere Navarro, A.V., Coord.): Derecho Sancionador Público del Trabajo, cit., p. 373.

143 STS, Cont-Admtivo, 22 noviembre 1989 (RJ 8355).

236144 Beneyto Calabuig, D.: Las infracciones laborales y el procedimiento sancionador, cit., p. 255. 
venga de consideraciones jurídicas diferentes de las alegadas por el interesado. Congruencia que, siguiendo lo dispuesto en el art. 138.2 LRJAP, obliga a que en la resolución no se puedan aceptar hechos distintos de los determinados en el curso del procedimiento, con independencia de su diferente valoración jurídica, pues de lo contrario se entraría en contradicción con lo previsto en el art. $24 \mathrm{CE}^{146}$.

Si en el tiempo de de seis meses desde la fecha del acta no hubiese recaído resolución, se inicia el cómputo del plazo de caducidad de treinta días establecido por el art. 43.4 LRJAP; transcurrido dicho lapso temporal, el procedimiento caduca, archivándose las actuaciones (art. 20 RD 928/1998). Ahora bien, la caducidad no supone por sí sola la prescripción de las acciones ${ }^{147}$; antes al contrario, es jurídicamente posible el reinicio de un nuevo procedimiento si no hubiera prescrito la infracción, tal y como dispone el art. 92 LRJAP $^{148}$.

La resolución se ha de notificar a los interesados, advirtiéndoles de los recursos que se pueden interponer contra ella, del órgano administrativo o judicial ante el que hubieran de presentarse y del plazo de interposición (art. 21.1 RD 928/1998). En el caso de imposición de sanciones pecuniarias, la resolución deberá expresar también el importe a ingresar, plazo, lugar y forma del pago en período voluntario y prevención de apremio de no ingresarse (art. 21.1 RD 928/1998). Se remitirá asimismo copia o comunicación de la resolución administrativa recaída en el procedimiento al funcionario que hubiese promovido el expediente, a los correspondientes organismos y entidades gestoras de la Seguridad Social (en el caso de que, en su momento, se les hubiese comunicado el acta de infracción y cuando la resolución imponga sanciones accesorias o declare la responsabilidad solidaria del empresario respecto de la devolución de las cantidades indebidamente percibidas por el trabajador), a los trabajadores afectados (cuando el acta de infracción se haya levantado con ocasión de accidente de trabajo o enfermedad profesional) y a los representantes legales de los trabajadores si la infracción recogida en el acta constituye vulneración de los derechos de libertad sindical o de representación colectiva (art. 21.1, 2, 3, 4, 5 y 6 respectivamente RD 928/1998).

Contra las resoluciones dictadas en el procedimiento sancionador se podrán interponer "Ios recursos administrativos y jurisdiccionales que legalmente procedan" (art. 54 LISOS), esto es, recurso de alzada, en el plazo de un mes, ante el órgano superior competente por razón de la materia (arts. 114 y 115 LRJAP y arts. 4, 22 y 23 RD

146 AA.VV (Sempere Navarro, A.V., Coord.): Derecho Sancionador Público del Trabajo, cit., p. 375.

147 SSTS, Cont-Admtivo, 22 noviembre y 20 y 22 diciembre 1998 (Ar. 9154, 9988 y 10221), 19 julio y 19 noviembre 1989 (Ar. 6034 y 8514), 30 junio y 10 julio 1990 (Ar. 5759 y 5846), 9 julio 1993 (Ar. 5767 ) y 29 enero 1994 (Ar. 348), 18 junio y 21 julio 2004 (RJ 5594 y 5569), 3 julio 2006 (RJ 7064) y 24 octubre 2007 (RJ 7497).

148 Estévez Goytre, R.: “La caducidad y la prescripción en el Derecho Administrativo Sancionador”, Actualidad Administrativa, núm. 46, 2000, pp. 1239 y ss. 
928/1998), cuya resolución agotará la vía administrativa (art. 23.1 RD 928/1998)149. Una vez transcurridos tres meses desde la interposición de dicho recurso sin que recaiga resolución, se podrá entender desestimado y quedará expedita la vía jurisdiccional correspondiente (art. 23.2 RD 928/1998). En todo caso, las resoluciones sancionadoras firmes en vía administrativa serán inmediatamente ejecutivas (art. 24 RD 928/1998). Y, en fin, transcurrido el plazo establecido en el art. 3.3 LPL, sin que se haya presentado el correspondiente proyecto de ley, el conocimiento de la impugnación judicial de las resoluciones administrativas relativas a "la impugnación de cualesquiera sanciones por todo tipo de infracciones de orden social" sigue estando atribuido al orden contencioso-administrativo, y no al social como había pretendido el art. 3.2 a) LPL, redactado conforme a la disposición adicional $5 .{ }^{a}$ LJCA $^{150}$.

\section{CONCLUSIÓN}

La relevancia social y económica de los valores e intereses tutelados por el Derecho del Trabajo "exige de modo particularmente intenso que los incumplimientos de la legislación laboral sean reprimidos por la Administración”'151. A tal objetivo sirve la LISOS, norma instrumental cuya finalidad se centra en prestar cobertura legal a la tipificación de las infracciones y sanciones, garantizando la efectividad del ordenamiento jurídico social y el respeto a los derechos subjetivos de los trabajadores, a cuyo efecto realizó un encomiable esfuerzo por ordenar y sistematizar el ejercicio de la técnica sancionadora administrativa laboral ${ }^{152}$, ampliándola y restableciendo la seguridad jurídica en su utilización ${ }^{153}$.

Esta disposición legal, caracterizada por introducir un fuerte intervencionismo administrativo en el ejercicio de la tutela sancionadora, vino a prever, minuciosa y exhaustivamente, todas las conductas sancionables, intentando constituir un auténtico “código sancionador en materia laboral”"154. Sólo cabe esperar, por tanto, que las futuras, y seguramente necesarias, modificaciones que incidan en la regulación de la materia sancionadora del orden social, se lleven a cabo (como hasta ahora se ha veni-

149 Cabe también la interposición de recurso potestativo de reposición (arts. 116 y 117 LRJAP) y recurso extraordinario de revisión (art. 108 LRJAP). Gutiérrez Alonso, J.J.: "Procedimiento sancionador y sistema de recursos administrativos en el Texto Refundido de la Ley de Infracciones y Sanciones en el orden social", cit., pp. 446 y ss.

150 Soro Mateo, B.: "La revisión judicial de las resoluciones sancionadoras de infracciones de orden social”, en AA.VV (Cavas Martínez, F. y Luján Alcaraz, J., Dirs.): Infracciones y sanciones en el orden social. Régimen jurídico, cit., pp. 459 y ss.

151 Montoya Melgar, A.: Jurisdicción y Administración de Trabajo. Extensión y límites de sus competencias, Madrid (Tecnos), 1970, pp. 118 y ss.

152 Rivero Lamas, J.: "Prólogo" a la obra de García Blasco, J.: Infracciones y sanciones en el orden laboral. Un comentario a la Ley 8/1998, de 7 de abril, Madrid (Civitas), 1989, p. 15.

153 Cavas Martínez, F.: “La tutela sancionadora en materia laboral: de la Ley 8/1988, de 7 de abril, sobre infracciones y sanciones en el orden social, al Real Decreto Legislativo 5/2000, de 4 de agosto, que aprueba el texto refundido de la Ley de Infracciones y Sanciones del Orden Social (I)", cit., p. 230.

154 García Blasco, J.: Infracciones y sanciones en el orden laboral. Un comentario a la Ley 8/1998, de 7 
do haciendo con carácter general) en el propio texto de la LISOS, sin dar nueva ocasión a la dispersión normativa preexistente ${ }^{155}$.

Escasa atención presta, sin embargo, este texto refundido a las reglas que debe observar el procedimiento sancionador, pues se limita, de un lado, a adoptar, como propios, los principios trazados por la LIT, y, de otro, a incorporar la referencia supletoria a la LRJAP, lo que supone la proyección sobre el especial ámbito referido a la potestad sancionadora en materia social del modelo procedimental que diseña la norma común ${ }^{156}$. Este particular mestizaje provoca algunas disfunciones merecedoras de corrección, entre las cuales, procede hacer referencia como más urgentes, muchas veces, en la práctica, las dos siguientes fundamentales: por una parte, es necesario reconsiderar la existencia de una actual fase instructora descafeinada y escasamente identificable en la que se mezclan las actuaciones del órgano resolutor y del órgano instructor, sin que lleguen a saberse a ciencia cierta las facultades de uno y otro durante la tramitación del expediente; por otra, deviene imprescindible cubrir la omisión de regulación de la prueba por el RD 928/1998, que desoye el expreso mandato contenido en la disposición adicional $4 \cdot{ }^{a}$ LIT $^{157}$.

155 Cavas Martínez, F.: “La tutela sancionadora en materia laboral: de la Ley 8/1988, de 7 de abril, sobre infracciones y sanciones en el orden social, al Real Decreto Legislativo 5/2000, de 4 de agosto, que aprueba el texto refundido de la Ley de Infracciones y Sanciones del Orden Social (II)", cit., p. 255.

156 Moreu Carbonell, E.: "Las especialidades del procedimiento sancionador en el orden social y para la liquidación de cuotas de la Seguridad Social. ¿Excesos en la potestad inspectora?”, Actualidad Laboral, núm. 19, 1999, p. 370.

157 Mercader Uguina, J.R. y Tolosa Tribiño, C.: "Notas al nuevo texto refundido de la Ley de Infracciones y Sanciones en el Orden Social”, Relaciones Laborales, T. II, 2000, p. 1074. 
